\title{
Crack path and regularities for ball-bearing fracture in the very high cycle fatigue regime
}

\author{
Andrey Shanyavskiy ${ }^{1}$ and Aleksey Soldatenkov ${ }^{1}$ \\ ${ }^{1}$ Aviation Register for the Russian Federation Airport Sheremetievo-1 PO Box 54 Moscow \\ region Chimkinskiy State 141426 Russia
}

March 3, 2022

\begin{abstract}
The process of fatigue spalling in the rings of ball bearings at durability exceeding $10^{8}$ cycles under in-service loading conditions is analyzed on the basis of fractography and the slices prepared in radial planes of rings. The cracks are shown to originate at subsurface from carbides inherent in the bearing steel or inclusions permissible by sizes for the material. Subsequently, the development of cracks perpendicular to the ring raceway surface takes place similarly as in the VHCF regime with the elliptical "fish-eye" formation. The subsequent crack growth was demonstrated step-by-step up to the ring material fragment separation. The total crack path by alternating stops of propagation and new crack nucleation under conditions of mixed-mode I + II + III mechanisms with the crack branching was discussed. In the final stage, the crack grows towards the ring raceway and either appears on the raceway surface or coalesce with a similar adjacent crack followed by fatigue spalling formation.
\end{abstract}

Crack path and regularities for ball-bearing fracture in the very high cycle fatigue regime

A.A. Shanyavskiy ${ }^{1), 2)}{ }^{*}$, A.P. Soldatenkov ${ }^{1)}$

1) Aviation Register for the Russian Federation, Airport Sheremetievo-1, PO Box 54, Moscow region, Chimkinskiy State, 141426, Russia

2) Institute of Computer Aided Design, 2nd Brestskaya street 19/18, Moscow, 123056, Russia

Abstract. The process of fatigue spalling in the rings of ball bearings at durability exceeding $10^{8}$ cycles under in-service loading conditions is analyzed on the basis of fractography and the slices prepared in radial planes of rings. The cracks are shown to originate at subsurface from carbides inherent in the bearing steel or inclusions permissible by sizes for the material. Subsequently, the development of cracks perpendicular to the ring raceway surface takes place similarly as in the VHCF regime with the elliptical "fish-eye" formation. The subsequent crack growth was demonstrated step-by-step up to the ring material fragment separation. The total crack path by alternating stops of propagation and new crack nucleation under conditions of mixedmode I+II +III mechanisms with the crack branching was discussed. In the final stage, the crack grows towards the ring raceway and either appears on the raceway surface or coalesce with a similar adjacent crack followed by fatigue spalling formation.

Keywords : bearing steel, in-service, spalling, very-high-cycle fatigue, crack path, mixed-mode

NOMENCLATURE

$a_{1}$ modification factor for reliability

$a$ ISO life modification factor, based on a systems approach of life calculation

area inclusion area, in $\mu \mathrm{m}^{2}$ 
$C$ basic dynamic capacity of the bearing, in newtons

$F$ dynamic equivalent radial load, in newtons

$H V$ Vickers hardness, in $\mathrm{kgf} / \mathrm{mm}^{2}$

$K_{z}$ factor depending on the geometric sizes of rings and balls, the number of balls, and accounting for the case which of the ring is rotated

$L_{10}$ basic rating life associated with $90 \%$ reliability, in million revolutions

$\mathrm{L}_{\mathrm{nm}}$ modified rating life, in million revolutions

$N$ life in terms of unit cycles from the action of a single ball at any point of the raceway surface

$p$ power in equation for predicted value of bearing life

$t_{h}$ bearing life, in hours

$V$ the rotational speed of bearing, in rpm

$\sigma_{\mathrm{eq}}$ equivalent uniaxial maximum tensile stress under standard experimental conditions

\section{INTRODUCTION}

The basic principle for bearing operation is the safe life criterion, i.e., damage of bearing as a part of a more complex structural element is not allowed for the period specified by the designer. Unfortunately, within the designed lifetime in-service, bearing failures occur, mainly, due to a violation of in-service conditions. Such cases have been thoroughly investigated and classified according to the various reasons for damage: excessive loads, misalignment, tight fits, lubricant failure, wear, corrosion, fretting, etc. ${ }^{1,2}$

The only possible reason for bearing failure at the conventional operating conditions is considered to be the development of the fatigue process in material. ${ }^{2,3}$ The term "conventional operating conditions" is referred to as "conditions which may be assumed to prevail for a bearing which is properly mounted and protected from foreign matter, adequately lubricated, conventionally loaded, not exposed to extreme temperature and not run at exceptionally low or high speed" in accordance with the Standard ISO 281:2007. ${ }^{4}$ The fatigue process is realized on the rolling contact surface by the spalling of material as a result of the action of repetitive sign-changing normal and tangential stress. Material spalling appears due to the development of crack initiated from the subsurface. The location of crack origin under the contact surface corresponds to the classic results of rolling contact calculations. ${ }^{5}$ In the zone of contact with the ball, the most intensive stress state for the rolling counterface surface is realized at a certain distance in depth.

However, fatigue spalling of the bearing elements occurs without a violation of in-service conditions, when the lifetime in-service of the bearings exceeds $10^{8}$ unit loading cycles, but within the designed life. The considered long durability corresponds to the very-high-cycle fatigue (VHCF) regime.

In addition, when bearing is designed, selected, and to be predicted its in-service life, the curves of data from the bench testing at various applied loads are used. Initially, test data were approximated by the Lundberg-Palmgren equation ${ }^{6,7}$ which is expressed as follows:

$L_{10}=[C / F]^{p},(1)$

where $L_{10}$ is bearing life that corresponds to the point at which $10 \%$ of the bearings will fail; $C$ is the basic dynamic capacity of the bearing based on the number of rolling elements, the roller length and diameter, and the contact angle; $F$ is applied load; $p$ is a power that is equal to: 3 for ball bearings, 4 for pure line contact bearings, or 10/3 for typical roller bearings. The restrictions for the application of Eq. (1) are provided in Standard $\mathrm{ISO}^{4}$ as the invalidity at "very light loads".

Subsequently, due to the improvement of the bearing steel quality, modification of bearing design, an increase in accuracy of manufacturing techniques, reduction of rolling surface roughness, the in-service bearing life 
became exceeding the durability predicted by Eq. (1) by more than one order. It leads to understanding that the conception of bearing life prediction is necessary to be changed and introducing the concept about the load level at which the plateau on the dependence of bearing life on load exists. The plateau level is referred to as fatigue load limit being an analogue of the fatigue limit which is applied for the description of material behavior under cyclic loading. This concept was discussed in the work ${ }^{8}$ where the necessity of introduction of fatigue limit load for bearings is stated and the model for bearing life is provided as it is expressed in Standard $\mathrm{ISO}^{4}$ :

$\mathrm{L}_{\mathrm{nm}}=\mathrm{a}_{1} \cdot \mathrm{a}_{\mathrm{ISO}} \cdot \mathrm{L}_{10},(2)$

where $\mathrm{L}_{\mathrm{nm}}$ is modified rating life, in million revolutions; $a_{1}$ is the modification factor for reliability, which is tabulated in Standard $\mathrm{ISO}^{4} ; a$ ISO is determined from the graphs provided in Standard $\mathrm{ISO}^{4}$ for various types of bearings and possible values of viscosity ratio, contamination factor, and load. Moreover, the maximum value of $a$ ISO is not exceeding the value of 50 .

Nowadays, the indicated approach is used in Standard ISO 281:2007 for the rolling bearing life prediction, though, in 2010, the papers ${ }^{9,10}$ were published where controversial arguments for the validity of conception of fatigue load limit for rolling bearings life ratings are provided. To confirm the absence of the limit, the data on the life of 7953 bearings ${ }^{11}$ and the test results of bearing steels performed in the wide range of durability ${ }^{12-14}$ are analyzed. The significant scatter in durability for the range of transition from VHCF to HCF is demonstrated. ${ }^{12-14}$

The curve for bearing life prediction is similar to the Wohler curve describing the metal fatigue behavior, where the fatigue load limit is estimated..$^{2,4}$ At the load levels below this value, the bearing failure is proposed to be impossible and its life of safe operation remains acceptable and reasonable for reliable replacement. Moreover, it is pointed out ${ }^{4}$ that at levels of Hertzian contact stress below the value of $1500 \mathrm{MPa}$, the rolling bearings wouldn't fail.

Due to the tendency of increasing the rotational speeds in modern structures applied, for example, to the gas-turbine engines, the durability exceeding the base for the determination of the so-called fatigue limit is possible to be reached for a very short time. The considered long durability of more than $10^{8}$ cycles can be realized with operating times not exceeding 200 hours within the designed life at stresses below the material fatigue limit and rotational speeds of more than 10,000 rpm. It is well-known, the behavior of materials at VHCF is fundamentally different from the processes that are implemented in the HCF and LCF regimes. ${ }^{15}$ When modeling the bearing behavior and predicting its life, the failure criteria corresponding to the mechanisms of fracture in the HCF region are utilized. Ignoring of possibility for the appearance of fracture mechanism, being specific for the VHCF region, results in the incorrect estimation of bearing life. In addition, the lifetime in-service of aircraft engines reaches 100,000 hours, and the period between adjacent overhauls is at least 2000 hours.

Moreover, the formation of fatigue spalling on the rolling surface without a violation of in-service conditions at low values of axial and radial loads is considered to be not critical since the development of fatigue process would be registered by the magnetic chip detector or increasing vibration, and based on these features, the bearing is worth replacing by the new one. ${ }^{2}$ However, for complex structures and assemblies and at high rotational speeds, the considered procedure of replacement may be impossible at the existing considerations on the bearing behavior. In addition, the high growth rate of fatigue spalling which was estimated by the increase in the mass of spalled material was established. ${ }^{16}$ This fact confirms the necessity of using the safe-life criterion for bearings.

The relevance of describing the bearing failure in the VHCF regime is also reasoned by the fact that the existing models applied to bearing damage in the VHCF regime are based on the consideration of either the damage initiation process followed by simulating and predicting of their development, or the fracture development of the already formed fatigue spalling, without describing the total kinetics from the moment of damage origination up to the final fracture stage. ${ }^{17-24}$ 
Based on the experimental investigations on the behavior of material of bearing rings under rolling contact fatigue conditions, a variety of models describing the initiation of fatigue spalling in the ring material due to the contact of the ball with the raceway surface and at the subsurface origin formation were proposed. ${ }^{17-19,25} \mathrm{In}$ several models, the result of prediction was in good agreement with the observation of the spalling process. The subsurface origin is formed around inclusion or inhomogeneity in material. ${ }^{20,21}$ The microstructure of material surrounding the inclusion at the zone of crack initiation differs from the microstructure of base material, and after etching, it is observed as White Etching Area (WEA). The indicated region forms the so-called "Butterfly Wings", the shape of which characterizes the initial stage of crack propagation in two directions out of inclusion. The orientation and inclination of cracks with regard to the raceway surface may be different, although the direction of crack growth which is parallel to the raceway surface and coincides with the ball movement direction is reported. ${ }^{20,26}$

At a distance from the fracture origin, the crack changes its initial propagation direction and starts growing towards the raceway surface followed by the spalling of the formed material fragment. ${ }^{26}$ The model is based on the considerations of possible or the most probable development of the material fragmentation process originated from inclusions by the following stages: 1 - "butterfly" formation; 2 - initial crack growth almost parallel to the raceway surface and in opposite directions from the origin; 3 - change of crack path towards the raceway surface; 4 - spalling of formed material fragment. ${ }^{26}$ In the conception, a single section is only considered, and unfortunately, the issues of crack branching and possible growth in the material volume which is perpendicular to the direction of ball movement are not discussed.

The fatigue spalling process with the formation of subsurface WEA layer and "butterfly wings" beneath this layer was investigated by using a ball-on-rod testing machine. ${ }^{27}$ The cylindrical specimens of AISI M50 steel are rotated and loaded with three balls resulting in a realization of maximum Hertzian contact stress of $6.4 \mathrm{GPa}$ which is approximately three times higher than the highest operational load in aircraft turbines during take-off. The microstructural evolution during rolling contact fatigue was analyzed at the number of overrollings from $10^{4}$ to $1,9 \times 10^{8}$. At maximum durability reached in tests, the layer of the WEA was formed with a higher microhardness value as compared with the material outside the zone. Although at the durability of $10^{4}$, no region with WEA was observed and the hardness remains constant as in the initial state. After reaching durability of $10^{8}$ overrollings, the "butterfly wings" below the layer of the WEA were identified with a cluster of carbides in the middle of the "butterfly". Instead of the martensite structure of the material in its initial state, the nanocrystalline microstructure inside the region of "butterfly wings" was established by transmission electron microscopy and the rings on diffraction patterns. The described observations allowed to make an assumption that the similar "butterflies" and cracks in the region of "butterfly wings" might be an origin for subsurface crack resulting in the fatigue spalling. ${ }^{27}$ However, it was not emphasized that the presented results indicate the realization of the stress state belonging to the VHCF regime.

Nevertheless, both appearance and absence of "butterfly" along with increase and decrease in microhardness of surface layer in bearing steels AISI 52100, AISI M50, and M50NiL were noted with regard to microstructural changes in material. ${ }^{25,28-31}$

On slices prepared perpendicular to the raceway surface, it was demonstrated experimentally ${ }^{32}$ that cracks initiated from inclusion may grow at different angles of inclination to the rolling contact surface. The process of fatigue spalling was not considered by stages, and because of this, it does not allow to analyze the total process of material spalling from the moment of crack origination to the separation of the material fragment.

For the case of elongated inclusions located on the rolling contact surface, the sequence of crack origination and propagation was analyzed depending on the orientation of inclusion with regard to the ball movement direction. ${ }^{22}$ The mechanism of fracture under rolling contact fatigue conditions in specimens with $\mathrm{MnS}$ inclusions oriented along the direction of ball movement was discussed. A vertical crack initiated on the surface propagated into material depth in a plane parallel to the ball movement direction. Then the crack grew in a plane perpendicular to the rolling direction. After the vertical crack sizes reached a critical value, the horizontal subsurface cracks were formed. It was noted that the ratio of vertical crack origination duration to the durability of the flaking process was higher if the elongated inclusion is oriented along the ball movement 
direction as compared with two configurations of inclusion orientation perpendicular to the rolling direction.

Moreover, the inclined cracks propagated from the surface were observed which originated not from inclusions but due to realized stress state. ${ }^{23}$ These cracks were revealed by using high frequency ultrasonic echography, optical and scanning electron microscopy and were demonstrated on the transverse slices. The conclusion was made that the highest stress state for the spalling process is realized on the contact surface, and the surface crack propagates under combined mode I-II loading conditions. It was pointed out that surface roughness and machine marks play a sufficient role in increasing the stress concentration for the surface crack origination as inclusions located on the surface.

Analysis of the presented information has shown that these cracks are initiated at the high level of applied load in the zone of material fragment formed before its separation from the raceway surface. And they may be secondary regarding the primarily appeared cracks close to or at a distance as well as from inclusions. Due to the lack of data on the fractographic analysis at the initial stage of crack formation, it is not possible to establish unambiguously that considered cracks were formed from surface or subsurface origin in the region of the first fragment of material fatigue spalling.

The development of the fatigue spalling process is detected in service at the various number of cycles at the moment of its appearance depending on the level of bearing loading. Accounting for the number of shaft revolutions and the number of balls in a bearing, the durability of $10^{10}$ cycles from the contact with balls is possible to be achieved at the moment of spalling zone formation. ${ }^{24}$ In Eq. (1) the bearing life is determined by the number of shaft revolutions. ${ }^{2,3}$ However, per one revolution, the number of unit cycles from the action of single balls at any point of the raceway surface can be calculated by the formula: $N=V \cdot t_{h} \cdot K_{z}$, where $V$ is the rotational speed of bearing, in rpm; $t_{h}$ is the bearing life, in hours; $K_{z}$ is a factor depending on the geometric sizes of rings and balls, the number of balls and accounting for the case which of the ring is rotated. For example, in the case of inner ring rotation for bearing with 10 balls per one total revolution, any point of the inner ring is affected by approximately $40 \%$ of balls.

Such long durability corresponds to the region of material fatigue fracture which is characterized by the different mechanism of damage accumulation as compared with the mechanisms at life less than $10^{8}$ cycles realized in the $\mathrm{HCF}$ region. ${ }^{33}$ In this case, both realized stress state of material below the contact surface, and the nature of metal fracture in the VHCF create the conditions for a specific fracture origin formation and affect significantly the sequence of fracture process up to the moment of material fragment spalling.

In the zone of ball contact with the raceway surface, the material is loaded by the compression and shear resulting in the simultaneous tension and shear in the subsurface. Moreover, the shear is realized due to the ball pressure, i.e., perpendicular to the raceway surface, and along the ball movement direction, i.e., parallel to the raceway surface. This stress state promotes the subsurface crack initiation by the VHCF mechanism. Therefore, for the fatigue spalling process realized in the range exceeding $10^{9}$ unit loading cycles of the bearing raceway surface, the initial subsurface damage accumulation mechanism is possible to be similar to the crack origination mechanism in the VHCF region for metals. However, the indicated mechanism of origin formation at a distance from the raceway surface and the initial stage of crack propagation were not demonstrated experimentally also due to the necessity of performing the long-time benchmark tests of bearings.

Due to the loading conditions and life of bearing at the moment of spalling formation, the cases with both mechanisms of crack origination (surface and subsurface) may exist. A similar possibility of fracture origin formation was demonstrated in fatigue tests of materials with durability of $10^{8}-10^{9}$ unit loading cycles. ${ }^{15,34-38}$ A new conception of metal behavior in the VHCF region and the evidence of the existence of transition from the $\mathrm{VHCF}$ to the $\mathrm{HCF}$ allows assuming that fatigue spalling on the raceway surface is possible to be initiated in the zones of material where for some reason or other, the limit state by the VHCF criterion is reached. However, the initiation of fatigue spalling followed by the crack propagation up to the moment of material fragment separation by stages was not demonstrated previously by means of metallography and fractography.

The results of a study on the rings of ball bearings used in the aircraft engines and failed in the VHCF regime 
from the moment of damage origination up to the formation of the final fatigue spalling of the material are presented below.

\section{MATERIALS AND METHODS}

The objects of research are the radial ball bearings 76-211R и 5-126215R included in the PS-90A and TV3$117 \mathrm{~A}$ engines, respectively. Engine failures occurred as a result of bearing failure. Investigated bearings were manufactured from similar steel but had different lives at the moment of fatigue spalling appearance in the rings (Table 1). From the bearings indicated in the table, two bearings designated by the symbol "** will be particularly considered. The bearings differ by the in-service loading conditions, the number of balls, rotational speed, as well as the diameters of rings and balls. The number of cycles per one revolution of the inner ring due to the ball pressure on the outer ring amounts to 4 and 6 for bearings $76-211 \mathrm{R}$ и $5-126215 \mathrm{R}$, respectively.

When the fault detection of bearings was performed, cracks were found on the raceway surface of the bearing rings (Fig. 1). The cracks were oriented perpendicular to the direction of ball movement. As well, several zones of developed material fatigue spalling process were revealed (Fig. $1 \mathrm{c}, \mathrm{d}$ ).

To estimate the material state of bearing rings, a complex metallophysical analysis was performed. The material of the bearing ring is a heat-resistant precipitation-hardening steel grade EI347 (the closest analogue of steel AISI M50) with the following chemical composition (in wt\%): $\mathrm{Fe}$ - balance, $\mathrm{Cr}-4.5, \mathrm{Mn}-0.3$, Mo $-0.2, \mathrm{Ni}-0.2, \mathrm{Si}-0.2, \mathrm{~V}-1.5, \mathrm{~W}-8.5$. The structure of the material in all rings corresponds to the declared grade of heat-treated material, recommended for the manufacturing of the bearing rings and balls, and consists of fine-needle martensite and carbides of tungsten and vanadium (Fig. 2). In the material, there are two types of carbides (Fig. 2c). The carbides are dispersed particles of the secondary solid phase namely, spherical carbides (less than $3 \mu \mathrm{m}$ in diameter) and angular carbides in the shape of polyhedra. The sizes of angular carbides are almost an order of magnitude larger than for spherical carbides. The ring material hardness determined by the Rockwell method is HRC62.5 and HRC61.5 for bearings 76-211R and 5-126215R, respectively. In both cases, the hardness of the bearing ring material meets the requirements of the technical specifications. It is worth noting that the complex analysis of ring material state had shown that a violation of in-service conditions in bearings did not occur.

The stages of initiation and development of cracks in the rings of ball bearings up to the final formation of the material spalling fragment were studied in several steps. One part of the identified cracks were opened for subsequent analysis of the fracture surface relief features. The other part of cracks was subjected to metallographic analysis by using the slices prepared perpendicular to the ring raceway surface and almost parallel to the direction of ball movement, to study the paths of cracks and their interaction with each other in the volume of the ring material by its layer-by-layer removal with a distance between adjacent sections of 0.1-0.3 mm. The deepest and most branched cracks observed in the slices were opened in order to discover the nature of origin formation, as in the study of cracks opened for fractographic analysis at the first step of the investigation.

\section{RESEARCH RESULTS}

The nature of origination and development of cracks observed on the raceway surface of the outer ring of the bearing and oriented perpendicular to the direction of the ball movement was studied on the fracture surfaces after the opening of the cracks formed in-service. The investigated cracks can be divided into two groups depending on the location of the fracture origin.

The first group consists of cracks with a subsurface origin (Fig. 3). The shape of the initial crack development zone is evidenced that it was formed without the crack emerging onto the raceway surface. In the focus of the origin, a particle, being a stress concentrator, is located. The second group of cracks, oriented perpendicular to the direction of the ball movement, consists of cracks that had not revealed a pronounced fracture origin, although, in some regions of the fracture surface near the raceway surface, smooth semi-elliptical zones formed into a small depth are observed (Fig. 4). 
The geometry of the initial crack development zone almost coincides with the already classical shape of the origination zone formed in the VHCF regime ("fish-eye"). However, the observed zone in the bearings has an elliptical rather than circular shape, and the major axis of the ellipse is almost parallel to the raceway surface. The contact effect of the ball on the raceway, combined with the stress concentration generated by the particle, has a decisive influence on the subsurface initiation of a fatigue crack.

The detected inclusions in the origins of subsurface cracks are located at a depth of 10-15 $\mu \mathrm{m}$ and 30-40 $\mu \mathrm{m}$ from the raceway surface in the ball bearings $76-211 \mathrm{R}$ and $5-126215 \mathrm{R}$, respectively. The nature of the inclusions was determined using local X-ray analysis. It was established that the content of such elements as $\mathrm{C}, \mathrm{V}$, and $\mathrm{W}$ in the composition of the particles is significantly higher in comparison with the content of the elements outside the particles for bearing 76-211R (Fig. 5). The content of Fe within the particles is almost an order of magnitude lower than outside them. Therefore, the particles can be identified as angular carbides that are inherent in the bearing material under investigation and are not defects of the manufacturing procedure. The sizes of angular carbides in the focus of subsurface fracture origins do not exceed the values allowed by the documentation regulating the material of bearing rings. The particles in the origins of subsurface cracks in the bearing 5-126215R are composed of such elements as $\mathrm{S}$ and $\mathrm{Al}$, i.e., chemical elements that are material contamination. Thus, it was established that the subsurface crack initiation in the bearing occurred from particles in the form of sulphide and aluminium inclusions, which, unfortunately, cannot be eliminated in the technology of steel production.

After the crack approached the raceway surface, its development into the depth of the ring stopped, and the subsequent growth occurred only due to an increase in crack length along the raceway surface. As a result, a step was formed at the deepest points of the elliptical boundary of the initial crack development zone, without in-depth crack movement. Thus, the shape of the crack front changed from initially elliptical to semi-elliptical. After the crack size along the raceway surface became several times larger than the in-depth crack size, the subsequent crack propagation along its total front both in-depth and along the raceway surface occurred.

The fracture surface area near the raceway surface within $10 \mu \mathrm{m}$ has a smoothed relief without features of the originally formed crack growth relief. Such relief was formed as a result of the mutual relative displacement of the crack faces perpendicular to the raceway surface with partial abrasive wear of the fracture surface and the movement of spherical particles with the formation of grooves (Fig. 6a). Using local X-ray analysis, it was found that spherical particles have an increased content of $\mathrm{W}$ and $\mathrm{V}$ and can be identified as particles of the hardening phase in the form of spherical carbides inherent in the bearing steel. Since the hardness of spherical carbides exceeds the hardness of the matrix, when the crack faces were compressed, the carbides were pressed into the matrix. As a result, on the softer matrix, the grooves of their movement were formed. This evidence indicates that the 3D stress state of the ring material is realized due to both the mutual relative displacement of the crack faces under shear conditions and the ball pressing in the bearing ring during its movement along the raceway.

The in-depth crack propagation outside the zone of the fracture origin was accompanied by the formation of relief with numerous slip planes, regions of intergranular fracture, and a cascade of rivers-like relief. It is worth noting that even in these regions of the fracture surface, the zones with grooves of the spherical carbide movement due to their pressing into the matrix under shear conditions are observed (Fig. 6b).

The paths of rectilinear cracks formed initially perpendicular to the direction of ball movement, together with the curvilinear cracks adjacent to them, were studied in several radial sections on the slices of the ring material passing through the raceway surface. It was established by the metallographic analysis of the slices that the initial crack growth in the depth of the material occurs in a plane almost perpendicular to both the raceway surface and the direction of ball movement. The cracks originate from inclusions located at a certain distance from the raceway surface (Fig. 7).

The successive crack development is accompanied by its multiple branching and a gradual transition to propagation by one of the most developed branches along the raceway surface (Fig. 8). It is worth noting 
that during its growth, the crack intersected the carbides by fracturing them or passed by if the cohesion between carbide and base material is insufficient (Fig. 9).

After increasing crack length up to a certain value in a direction almost parallel to the raceway surface, the coalescence with an adjacent crack that has developed in-depth of ring occurs, or the crack turns independently towards the raceway surface (Fig. 10). The crack coalescence does not take place along the total length of the crack front. Part of the crack front remains independent, therefore in some sections, a fragment of the crack path without emerging the raceway surface and without connecting to an adjacent crack can be observed. When analyzing the sections, which are located closer to the middle of the raceway, the already existing connection between the fragment of the adjacent crack fronts is revealed (Fig. 10).

After a large part of the front of one crack approaches another subsurface crack, the material fragment is separated, which finally leads to the initiation of the material fatigue spalling process.

To establish the nature of origin formation for the cracks investigated in slices and to confirm the revealed regularities of its subsurface initiation, one of the cracks was opened. It was found that in the origin of the subsurface crack, an angular carbide is located.

Thus, based on the performed research, the kinetics of bearing ring fracture in the VHCF regime with the formation of final fatigue spalling is described as follows. The intensive mixed-mode conditions are realized below the raceway surface due to ball pressure. At the small distance from the raceway surface and with the existence of inclusion in material, the fatigue crack at the boundary of inclusion started originating. At the first stage, a subsurface crack propagated with the formation of an elliptical front in a plane oriented perpendicular to both the raceway surface and the direction of ball movement under the mixed-mode I-II-III loading conditions. At the next stage, after the crack approached the raceway surface, its development is realized only by increasing the total length along the raceway surface without growing into the material. At the third stage, only after reaching a certain critical length, the crack propagates simultaneously inside the material and along the raceway surface of the bearing ring. After the crack has grown deeper inside the material in a plane perpendicular to the raceway surface up to a certain length, an independent crack origination takes place almost perpendicularly to the plane of initial development. Subsequently, the crack propagation occurs as a cascade of repeated events. The crack growth parallel to the raceway surface is realized under the domination of mode II loading conditions, followed by coalescence with an adjacent crack. Thus, resulting from the branching of the cracks, a fragment of the ring material is formed (see Fig. 10), which then is separated from the ring raceway, leading to the initial stage of the fatigue spalling process.

\section{DISCUSSION}

Based on the presented results it can be argued that existing fatigue curves for bearings, which are described by Eqs. (1) or (2), do not reveal the fact that in the range of life exceeding $10^{8}$ cycles, the fatigue cracks originate by the mechanism which is different as compared with the mechanism of crack initiation at the lower durability range. Moreover, as performed analysis had shown the part of cracks were initiated from raceway surface, and it corresponds to the fact that in the transitional region from VHCF to HCF, two modes of crack origination belonging to two different fracture mechanisms (surface and subsurface) may be observed simultaneously. ${ }^{39,40}$

Therefore, it is obvious that fatigue curves for bearings with regard to the durability range up to $10^{8}$ cycles plotted on results of bench tests do not allow to predict the bearing durability greater than $10^{9}$ cycles, where material behavior at the crack initiation is different and necessary to be investigated.

The fatigue curve for bearings should have at least two branches and the range of bimodal life distribution between them. Based on the estimated durability, the above-considered cases of bearing failures are situated in the range of bimodal fatigue life distribution. Therefore, it can be assumed that the appearance of surface and subsurface fatigue cracks in the same zone of raceway surface was due to two simultaneous modes of crack initiation at the realized stress level and durability of $10^{8}-10^{9}$ cycles. In addition, the initiation oa subsurface crack is appeared to be dependent on the size of inclusion and its in-depth location with regard 
to the raceway surface.

The stress state of ring material was estimated by the size of inclusions from which the cracks were propagated. The formula proposed by Y. Murakami ${ }^{34}$ was used where $\sigma_{\mathrm{w}}$ was replaced by $\sigma_{\text {eq }}$ which is equivalent stress under standard uniaxial tensile conditions and expressed as follows:

$\sigma_{\mathrm{eq}}=1.56 \times[H V+120] /\left[(\text { area })^{1 / 2}\right]^{1 / 6},(3)$

where $H V$ is Vickers hardness, area is determined by the inclusion size. The equivalent stress represents the strain energy density ${ }^{41,42}$ and accounts for the influence of the multiparametric external action. Thus, equivalent stress is invariant which level can be reached in different ways, i.e., at various combinations of parameters characterizing the external action. It means that the equivalent stress incorporates the influence of the inclusion sizes, their location, effects of the environment temperature and its composition, the levels of applied stress, multiaxiality, rotational speed, etc. The equivalent stress level is an energetic characteristic and corresponds to the value of energy dissipated by material which was applied by the various combinations of external action parameters.

The calculations performed by Eq. (3) had shown that for all cases of subsurface crack initiation, the equivalent stress level was in the range of 900-955 MPa that approximately $35 \%$ lower than the value of fatigue limit for contact stress which is indicated as $1500 \mathrm{MPa} .{ }^{4}$ Concerning the steel grade EI347, the established stress range is close to the range of bimodal fatigue life distribution. Therefore, it can be considered that discussed cases of bearing failures initiated from the inclusions of different nature were realized in the bifurcation region, i.e., the bimodal fatigue life distribution. In addition, the tensile component of stress is dominant in the subsurface area which is created due to the ball pressure. It is the tensile rather than shear component of stress that governs the crack origination (Fig. 11). Consequently, the model describing the considered bearing failures is required to account for the indicated effect.

Initially, on the raceway surface, the cracks appeared perpendicular to the ball movement direction under combined shear and compressive loading conditions of ring material due to the ball pressure during its rolling. The regular crack appearance along the raceway reveals the wave nature of the maximum contact load influence during the rotation of bearing. The wave period of maximum contact load influence is manifested in regular space among the cracks.

Subsequently, the development of the fracture process below the raceway surface from the indicated cracks takes place with the formation of curvilinear crack cascades between the initially originated rectilinear cracks as well in planes that are parallel to the raceway surface. The curvilinear cracks on the raceway surface have resulted from their initial formation under mixed-mode I+II+III loading conditions inside the material volume. The cracks appeared on the raceway surface that led to the primary separation of a material fragment. Then the cascade of spalling process intensified that corresponded to the gradual spalling of material by the boundary of curvilinear cracks and formation of extensive zones of material fatigue spalling with separation of its fragment.

\section{CONCLUSION}

The process of fatigue spalling formation in ball bearings without violation of in-service conditions in the VHCF regime was studied and described from the initiation moment up to the formation of the material fragment for final separation from the ring.

It was established that the subsurface crack originates from carbides or inclusions inherent in the bearing steel investigated. Subsequently, the initial crack growth occurs with the "fish-eye" formation in the plane perpendicular to both the ring raceway surface and the direction of ball movement. When the crack approaches the raceway surface, its in-depth propagation stops, and the crack development along the raceway surface dominates. The subsequent crack growth occurs along the total crack front by alternating stops of propagation and new crack nucleation under mixed-mode I+II+III loading conditions. Then, at a certain depth, the cracks proceed to propagate almost parallel to the surface. At the final stage, the crack moves 
towards the ring raceway, and either approaches the raceway surface or coalesces with a similar adjacent crack followed by the separation of a ring material fragment.

\section{Acknowledgments}

The work was supported by RSF, grant N19-19-00705.

\section{Data Availability Statement}

The data that support the findings of this study are available from the corresponding author upon reasonable request.

\section{References}

1. Korostashevskiy RV, Zaitcev AM. Aviation Rolling Bearings.Moscow: Oborongiz; 1963.

2. Harris TA, Kotzalas MN. Rolling Bearing Analysis . Boca Raton: CRC/Taylor \& Francis; 2007.

3. Perel LY. Rolling bearings: Calculation, design and maintenance of supports. Handbook. Moscow: Mashinostroenye; 1983.

4. ISO 281:2007: "Rolling Bearings - Dynamic Load Ratings and Rating Life," International Organization for Standardization, Geneva, 2007.

5. Hertz H. On the contact of rigid elastic solids and on hardness. In:Miscellaneous Papers . London: MacMillan; 1896:163-183.

6. Lundberg G, Palmgren A. Dynamic Capacity of Rolling Bearings.Acta Polytech Sc Me . 1947;1(3): 1-52.

7. Lundberg G, Palmgren A. Dynamic Capacity of Rolling Bearings. Acta Polytech Sc Me . 1952;2(4): 96-127.

8. Ioannides E, Harris TA. A New Fatigue Life Model for Rolling Bearings. J Tribol-T ASME . 1985;107(3): 367-377. https://doi.org/10.1115/1.3261081

9. "ISO 281:2007 bearing-life standard - and the answer is?" Tribol Lubr Technol . 2010;7: 34-43.

10. Zaretsky EV. In search of a fatigue limit: A critique of ISO Standard 281:2007. Tribol Lubr Technol . 2010;8: 30-40.

11. Harris TA, McCool JI. On the Accuracy of Rolling Bearing Fatigue Life Prediction. J Tribol-T ASME . 1996;118(2): 297-310. https://doi.org/10.1115/1.2831299

12. Tosha K, Ueda D, Shimoda H, Shimizu S. A Study on P-S-N Curve for Rotating Bending Fatigue Test for Bearing Steel. Tribol T . 2008;51(2): 166-172. https://doi.org/10.1080/10402000801918031

13. Shimizu S, Tsuchiya K, Tosha K. Probabilistic Stress-Life (P-S-N) Study on Bearing Steel Using Alternating Torsion Life Test. Tribol T . 2009;52(6): 807-816. https://doi.org/10.1080/10402000903125345

14. Sakai T. Review and Prospects for Current Studies on Very High Cycle Fatigue of Metallic Materials for Machine Structure Use. In: Allison JE, Jones JW, Larsen JM, Ritchie RO, eds. Proceedings of the Forth International Conference on Very High Cycle Fatigue (VHCF-4) . Ann Arbor: TMS; 2007:3-12.

15. Shanyavsky AA. Scales of metal fatigue cracking. Phys Mesomech . 2015;18(2): 163-173. https://doi.org/10.1134/S1029959915020095

16. Rosado L, Forster NH, Thompson KL, Cooke JW. Rolling Contact Fatigue Life and Spall Propagation of AISI M50, M50NiL, and AISI 52100, Part I: Experimental Results. Tribol T . 2009;53(1): 29-41. http://doi.org/10.1080/10402000903226366

17. Sadeghi F, Jalalahmadi B, Slack TS, Raje N, Arakere NK. A Review of Rolling Contact Fatigue. $J$ Tribol-T ASME . 2009;131(4): 041403 (15 pages). https://doi.org/10.1115/1.3209132 
18. Keer LM, Bryant MD, Haritos GK. Subsurface and surface cracking due to Hertzian contact. J Lubric Tech-T ASME . 1982;104(3): 347-351. https://doi.org/10.1115/1.3253217

19. Chen L, Chen Q, Shao E. Study on initiation and propagation angles of subsurface cracks in GCr15 bearing steel under rolling contact. Wear . 1989;133(2): 205-218. https://doi.org/10.1016/0043-1648(89)90036-7

20. Lewis MWJ, Tomkins B. A fracture mechanics interpretation of rolling bearing fatigue. P I Mech Eng J-J Eng . 2012;226(5): 389-405. https://doi.org/10.1177/1350650111435580

21. Lamagnere P, Fougeres R, Lormand G, Vincent A, Girodin D, Dudragne G, et al. A Physically Based Model for Endurance Limit of Bearing Steels. J Tribol-T ASME . 1998;120(3): 421-426. https://doi.org/10.1115/1.2834565

22. Nakai Y, Shiozawa D, Kikuch S, Saito H, Nishina T, Makino T, et al. Observation of Flaking Process in Rolling Contact Fatigue by Laminography Using Ultra-bright Synchrotron Radiation. MATEC Web Conf, FATIGUE 2018 . 2018;165: 11002 (8 pages). https://doi.org/10.1051/matecconf/201816511002

23. Nelias D, Dumont ML, Champiot F, Vincent A, Girodin D, Fougeres R, et al. Role of Inclusions, Surface Roughness and Operating Conditions on Rolling Contact Fatigue. J Tribol-T ASME . 1999;121(2): 240-251. https://doi.org/10.1115/1.2833927

24. Gabelli A, Lai J, Lund T, Rydén K, Strandell I, Morales-Espejel GE. The fatigue limit of bearing steels - Part II: Characterization for life rating standards. Int J Fatigue . 2012;38: 169-180. https://doi.org/10.1016/j.ijfatigue.2011.12.006

25. Forster NH, Rosado L, Ogden WP, Trivedi HK. Rolling Contact Fatigue Life and Spall Propagation Characteristics of AISI M50, M50 NiL, and AISI 52100, Part III: Metallurgical Examination. Tribol T . 2009;53(1): 52-59. http://doi.org/10.1080/10402000903226317

26. Contact fatigue of steel for rolling bearings. Bulletin of iron and steel industry abroad . 2011;2: 47-48.

27. Pritz L, Marsoner S, Ebner R, Fluch R, Tatschl A, Münzer R. Investigation Into Microstructural Changes Due To The Rolling Contact Fatigue Of The AISI M50 Bearing Steel. WIT transactions on engineering sciences . 2015;91: 35-45. http://doi.org/10.2495/SECM150041

28. Braza J, Pearson P, Hannigan C. The Performance of 52100, M-50, and M-50 NiL Steels in Radial Bearings. SAE Technical Paper . 1993; 932470. https://doi.org/10.4271/932470

29. Voskamp AP, Österlund R, Becker PC, Vingsbo O. Gradual changes in residual stress and microstructure during contact fatigue in ball bearings. Met Technol . 1980;7(1): 14-21. https://doi.org/10.1179/030716980803286676

30. Swahn H, Becker PC, Vingsbo O. Martensite decay during rolling contact fatigue in ball bearings. Metall Trans A . 1976;7(8): 1099-1110. https://doi.org/10.1007/bf02656592

31. Martin JA, Borgese SF, Eberhardt AD. Microstructural Alterations of Rolling Bearing Steel Undergoing Cyclic Stressing. J Basic Eng-T ASME . 1966;88(3): 555-565. https://doi.org/10.1115/1.3645902

32. Shimoji I, Natori M, Hidaka H, Miyamoto Y. Effect of neighboring-microstructure on the rolling contact fatigue around non-metallic inclusion. MATEC Web Conf, FATIGUE 2018 . 2018;165: 04015. https://doi.org/10.1051/matecconf/201816504015

33. Shanyavskiy AA. Modelling of fatigue fracture in metals. Synergetics in aviation . Ufa: Monografy; 2007.

34. Murakami Y. Metal Fatigue: Effects of Small Defects and Nonmetallic Inclusions . Oxford: Elsevier; 2002.

35. Bathias C, Paris PC. Gigacycle fatigue in mechanical practice . NY: Marcel Dekker; 2005. 
36. Shanyavskiy A, Banov M. The twisting mechanism of subsurface fatigue cracking in Ti-6Al-2Sn-4Zr-2Mo-0.1Si alloy. Eng Fract Mech . 2010;77(11): 1896-1906. https://doi.org/10.1016/j.engfracmech.2010.04.011

37. Sakai T, Li W, Lian B, Oguma N. Review and new analysis on fatigue crack initiation mechanisms of interior inclusion-induced fracture of high strength steels in very high cycle regime. In: Berger C, Christ H-J, eds. Proceedings of Fifth International Conference on Very High Cycle Fatigue (VHCF-5) . Berlin: DVM; 2011:19-26.

38. Shanyavskiy AA. Ultrahigh plasticity behavior of metallic materials in the ultra-highcycle (or gigacycle, very-high-cycle) fatigue regime.Key Eng Mat . 2016;664: 231-245. https://doi.org/10.4028/www.scientific.net/kem.664.231

39. Shanyavskiy AA, Soldatenkov AP. Metallic materials fatigue behavior: scale levels and ranges of transition between them. Int J Fatigue. 2022 (In Press). https://doi.org/10.1016/j.ijfatigue.2022.106773

40. Shanyavskiy AA, Nikitin AD, Soldatenkov AP. Very High Cycle Fatigue in metals. Synergetics and physical mesomechanics. Moscow: Fizmatlit; 2021.

41. Shanyavskiy AA. Equivalent Uniaxial Cyclic Tensile Stress as an Energy Characteristic of Metal Fatigue under Multiparameter Loading.Phys Mesomech . 2018;21(6): 483491.https://doi.org/10.1134/S1029959918060024

42. Shanyavskiy A. Uniaxial equivalent of stress and stress intensity factor in Mode I crack opening for fatigued metals subjected to multi parametric external loading. MATEC Web Conf, FATIGUE 2018 . 2018;165: 13003. https://doi.org/10.1051/matecconf/201816513003

\section{Tables}

Table 1. Information on the life of the ball bearings investigated.

\begin{tabular}{llll}
\hline No & Life, hours & Life, number of engine operational cycles & Rotational speed, rpm \\
\hline ball bearings $76-211 \mathrm{R}$ & ball bearings $76-211 \mathrm{R}$ & ball bearings $76-211 \mathrm{R}$ & ball bearings $76-211 \mathrm{R}$ \\
1 & 1082 & 162 & 11963 \\
2 & 796 & 189 & \\
3 & 164 & 93 & \\
4 & 411 & 154 & ball bearings 5-126215R \\
$5^{*}$ & 175,4 & - & 19000 \\
ball bearings 5-126215R & ball bearings 5-126215R & ball bearings 5-126215R & \\
1 & 39 & - & \\
2 & 46 & - & \\
$3^{*}$ & 993 & - & \\
4 & 112 & & \\
\hline
\end{tabular}

Notion. The ball bearings considered in detail below are designated by *

Figures 


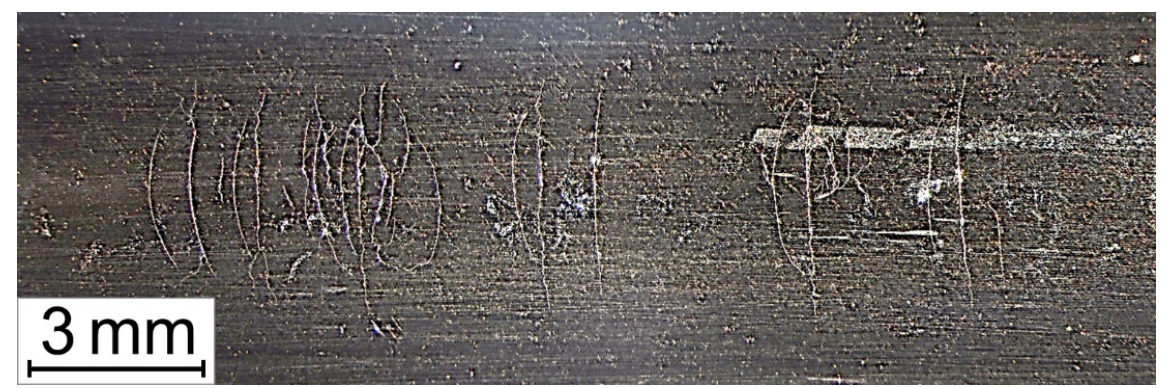

a)

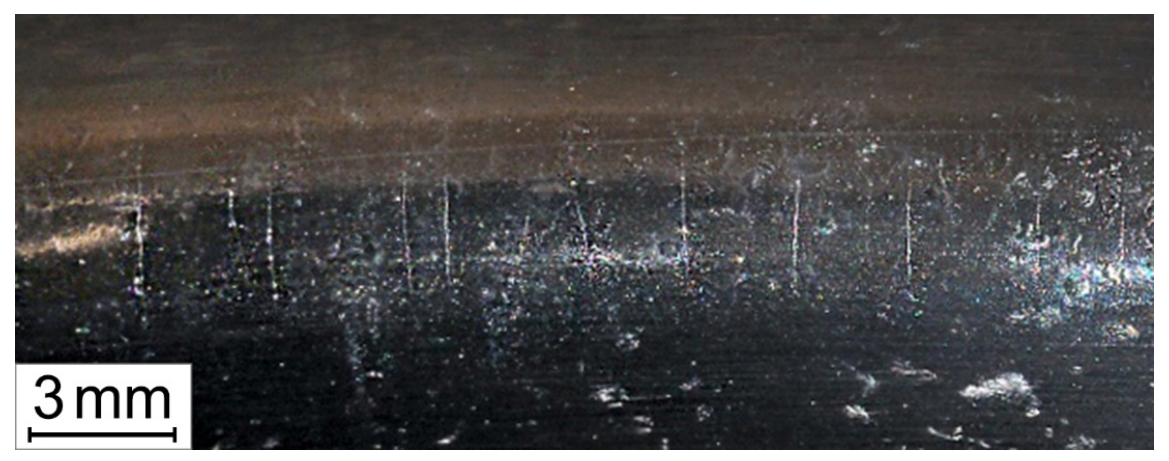

b)

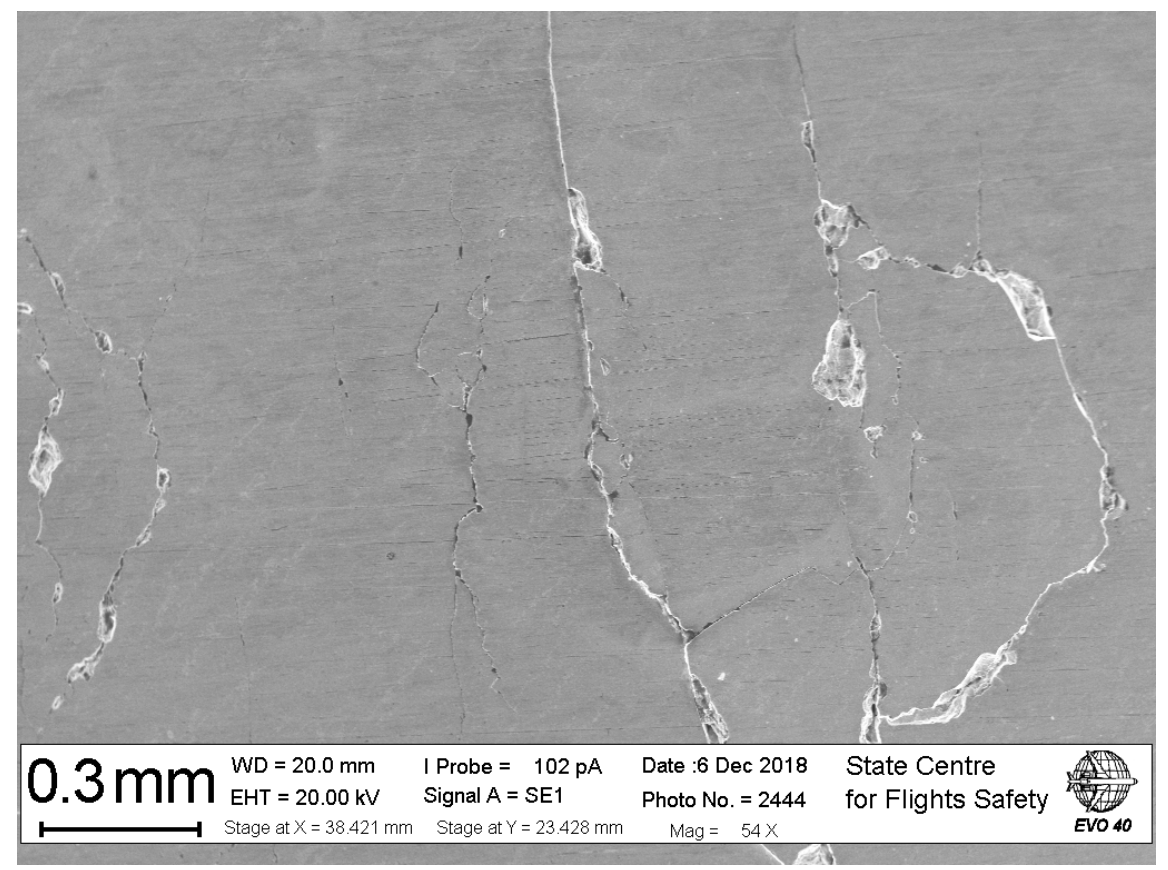

c) 


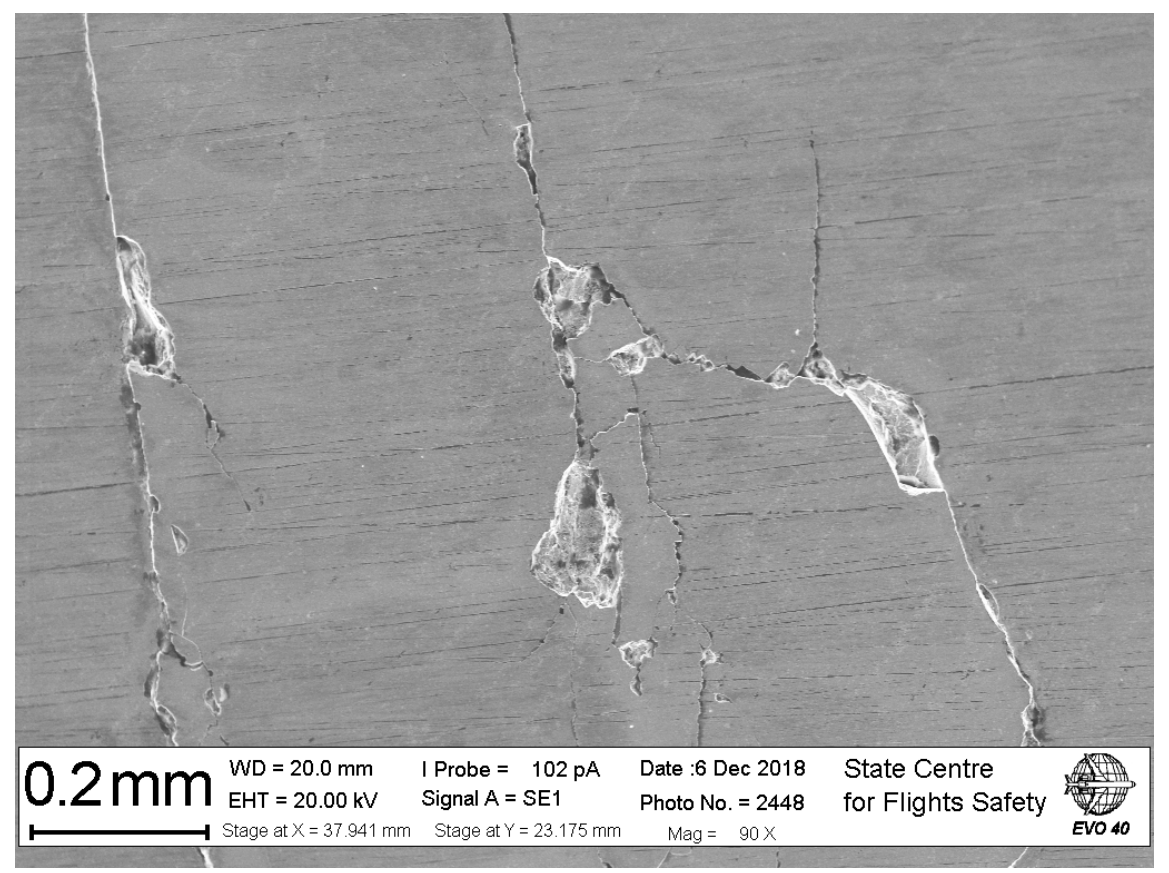

d)

Fig. 1.

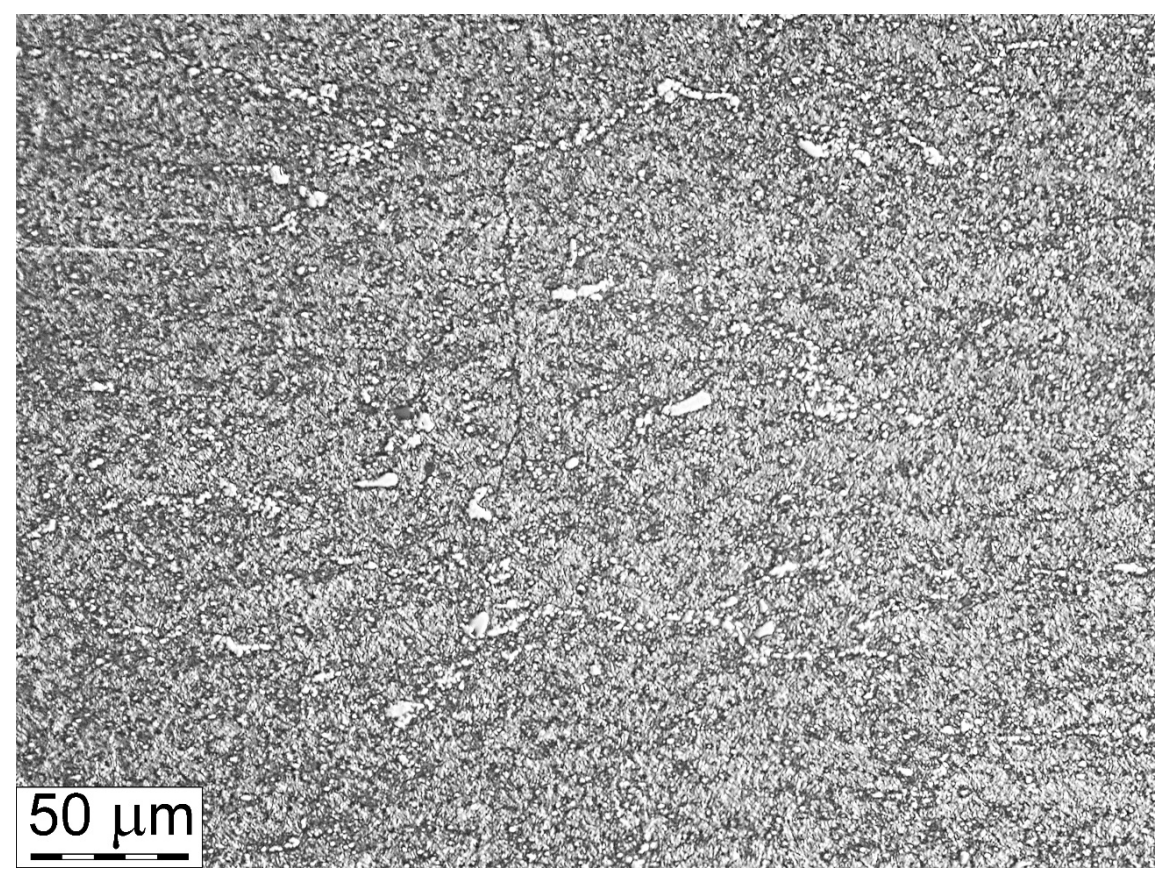

a) 


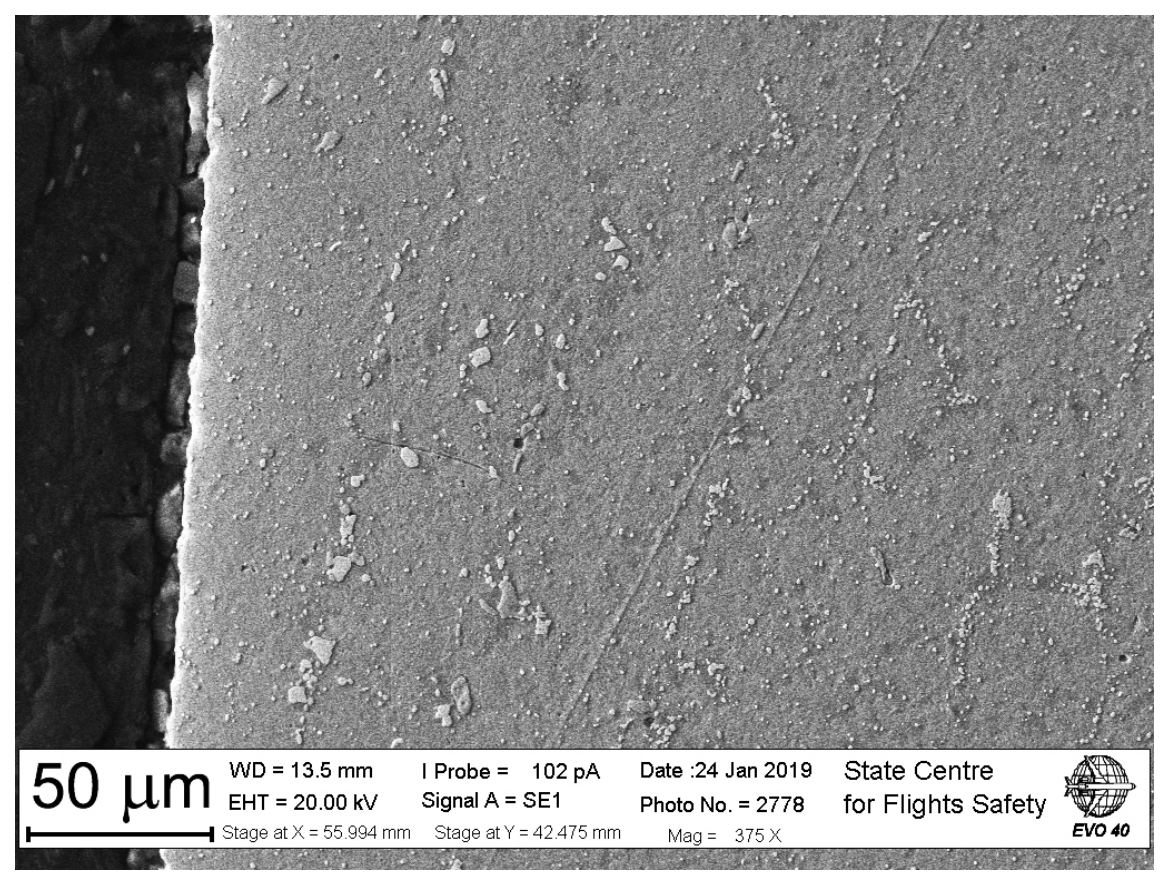

b)

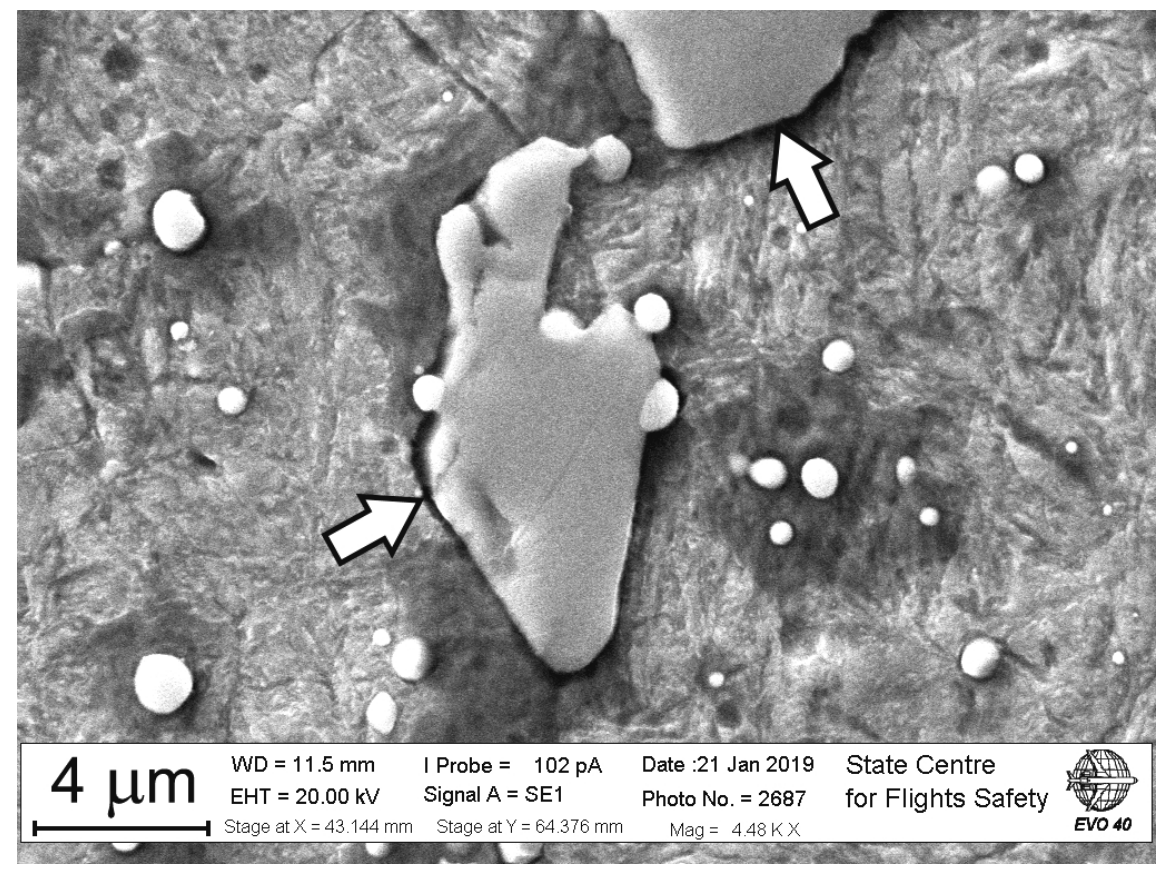

c)

Fig. 2. 


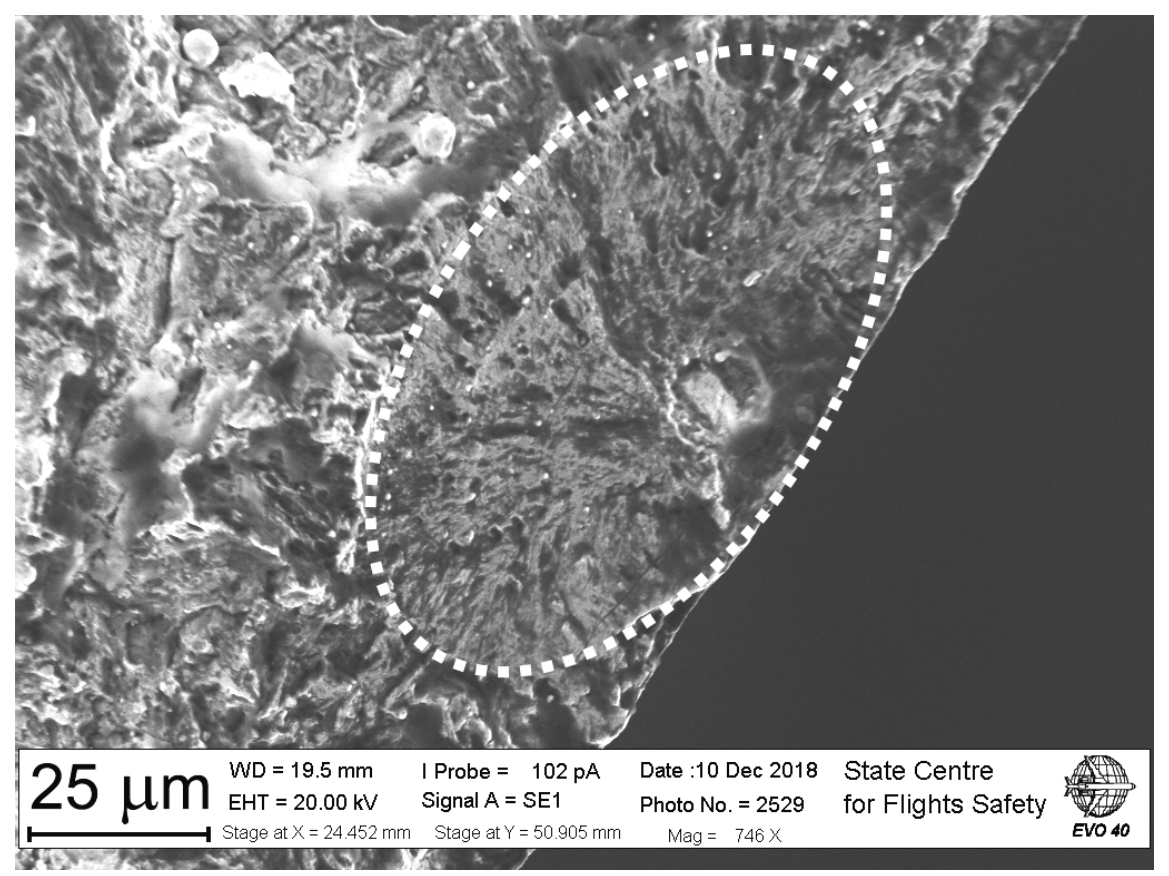

a)

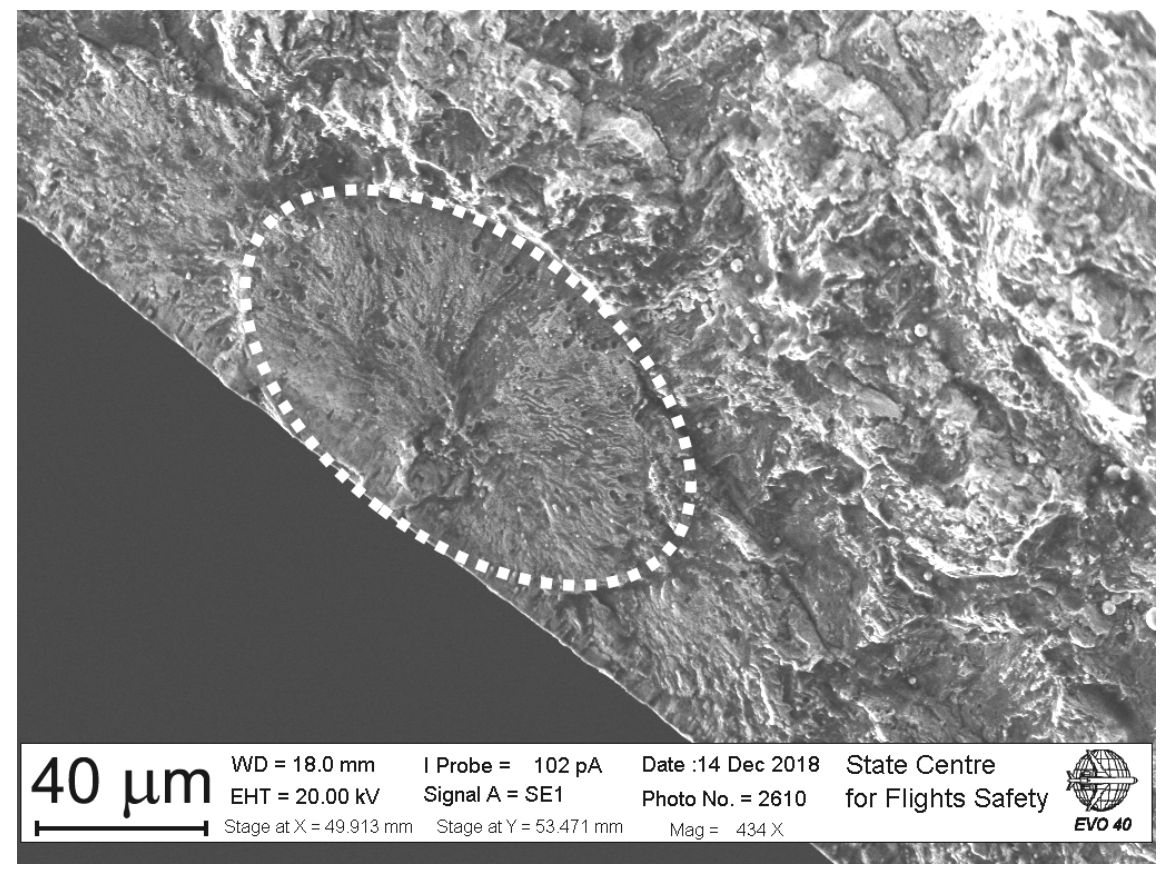

b) 


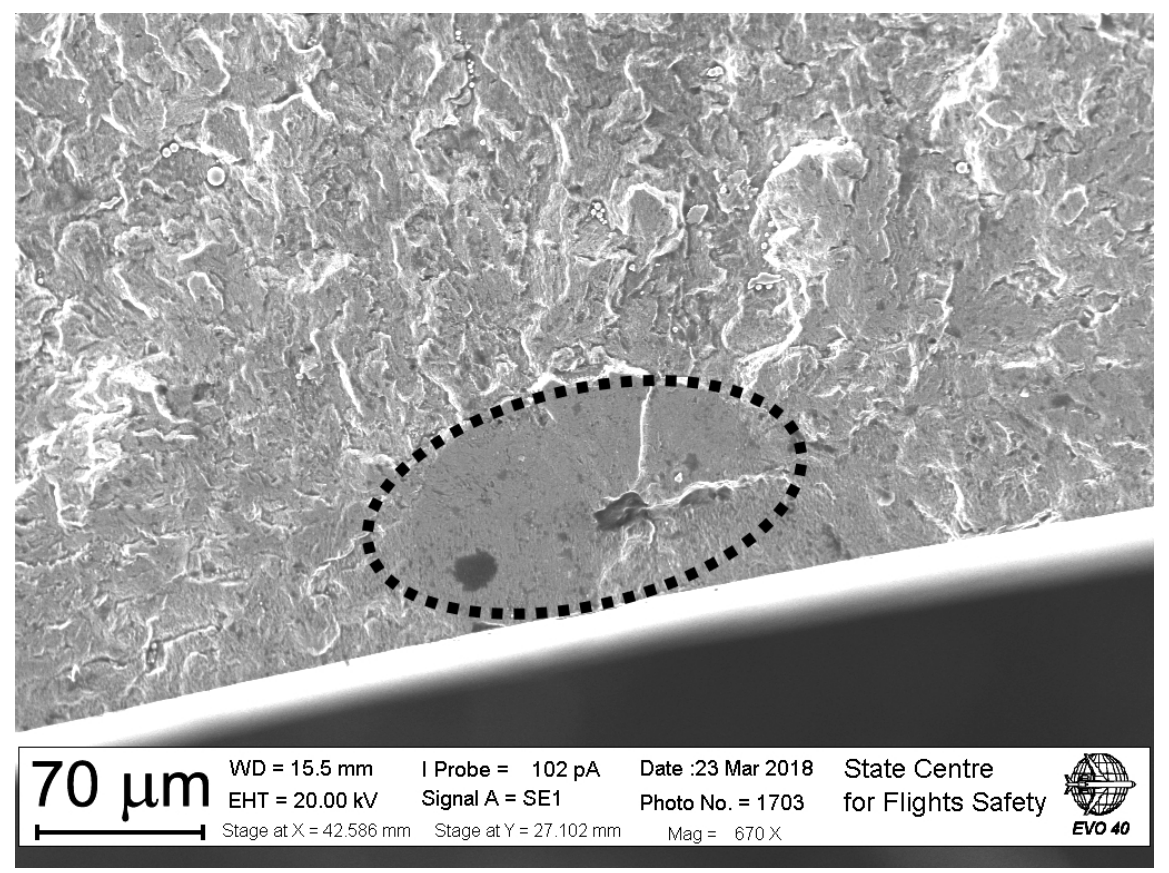

c)

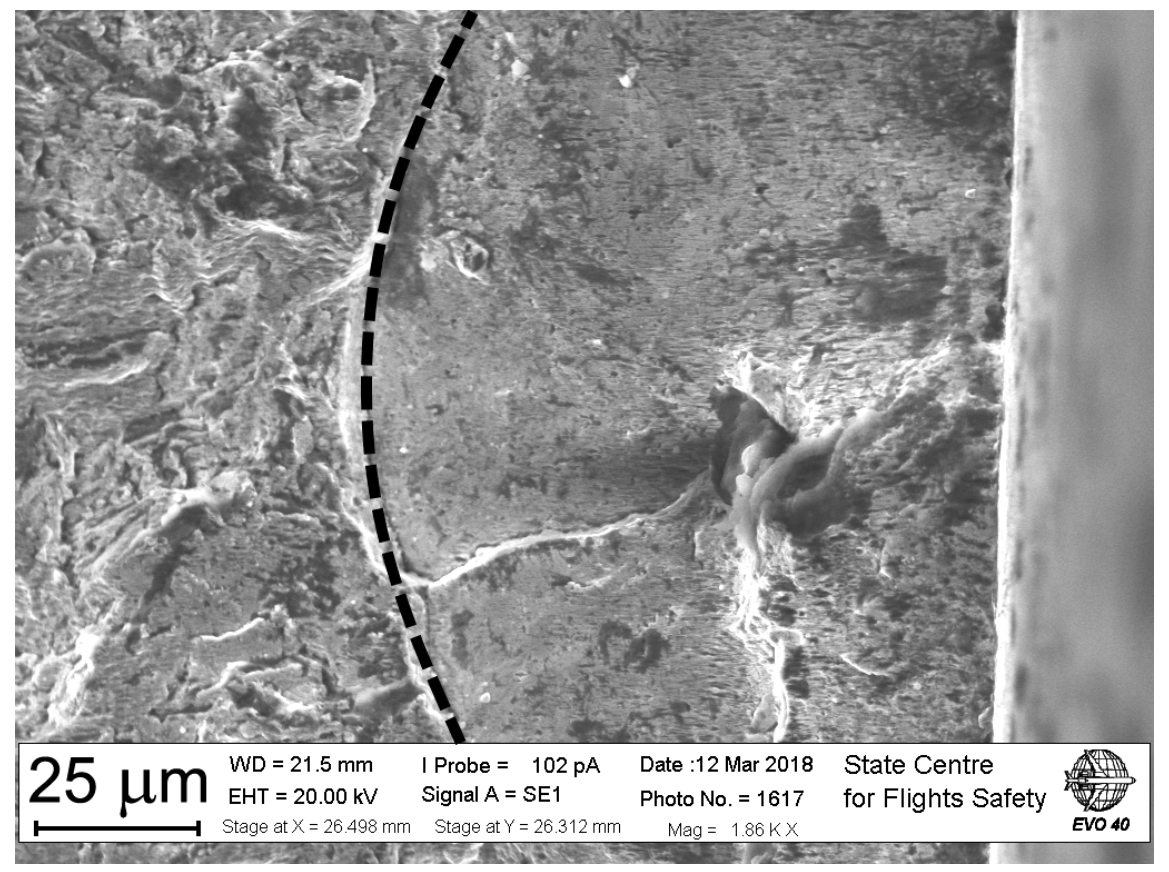

d)

Fig. 3. 


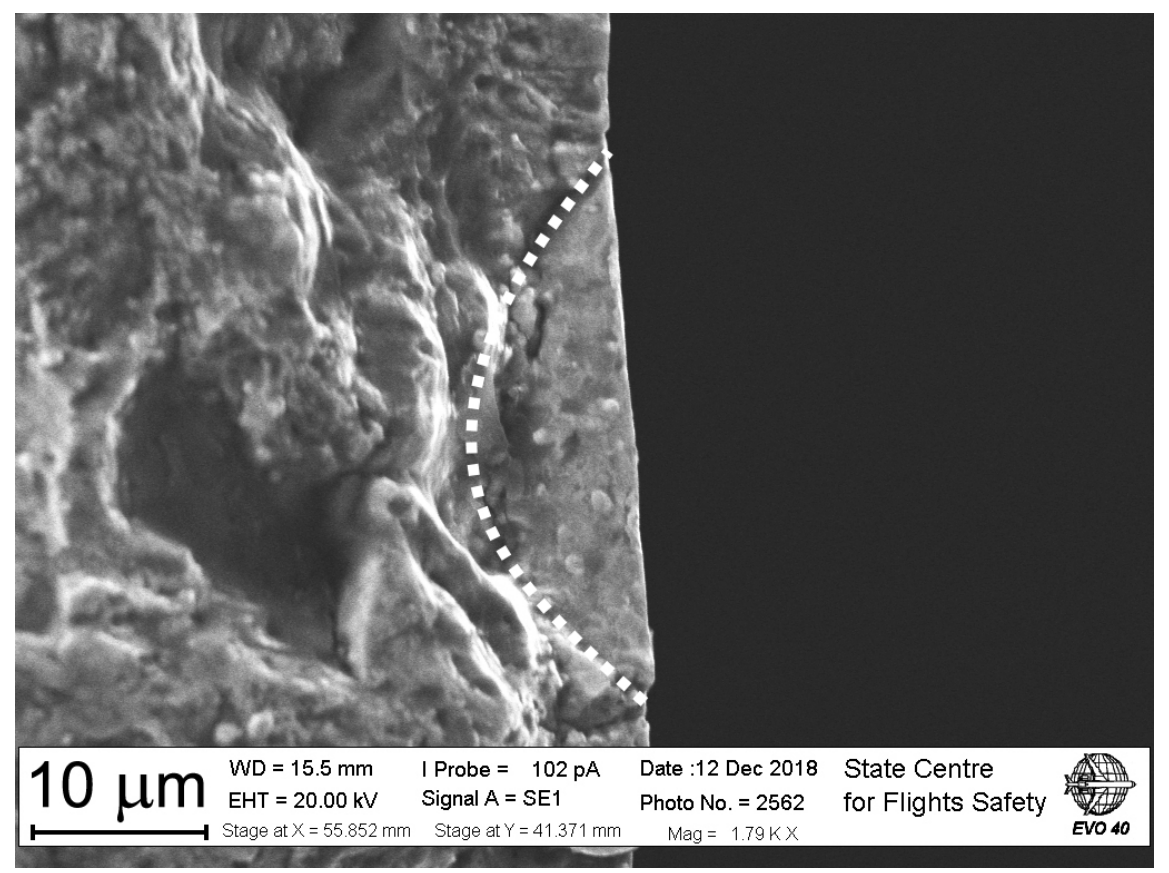

a)

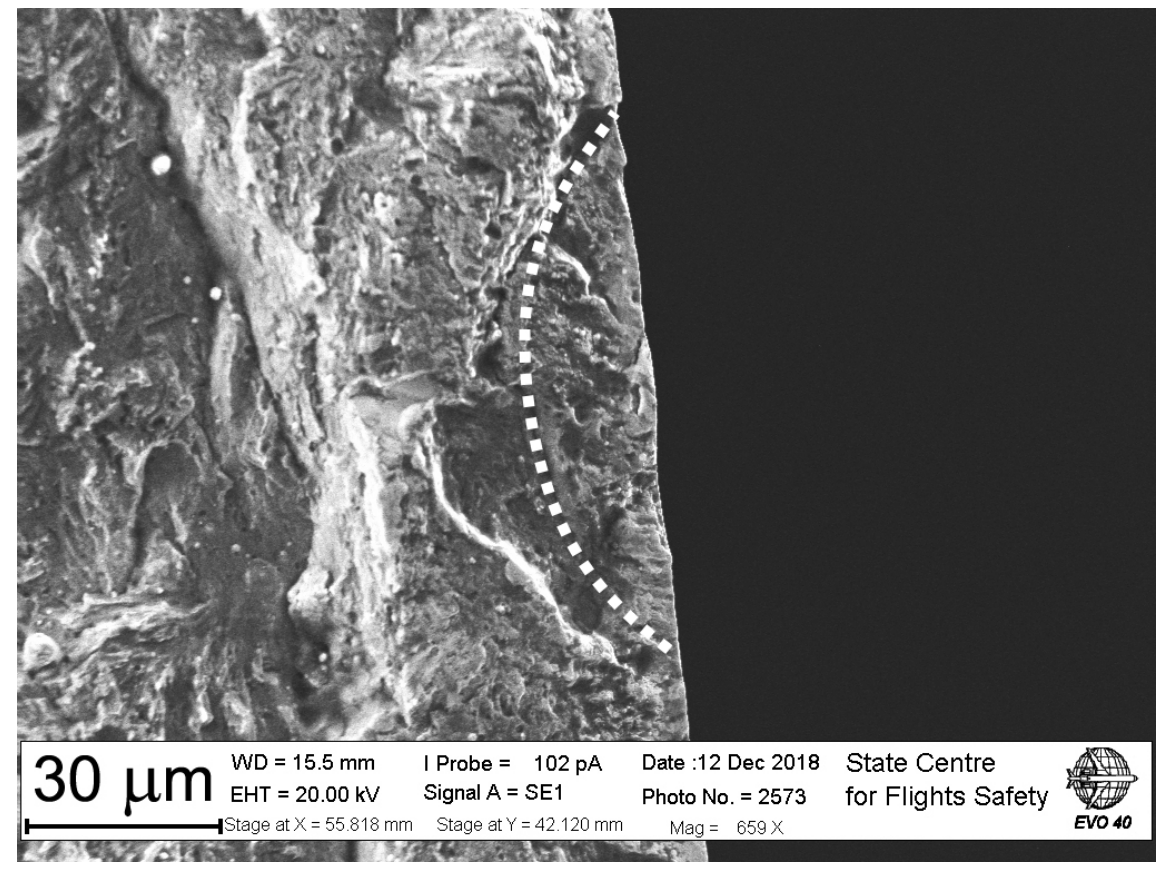

b)

Fig. 4. 


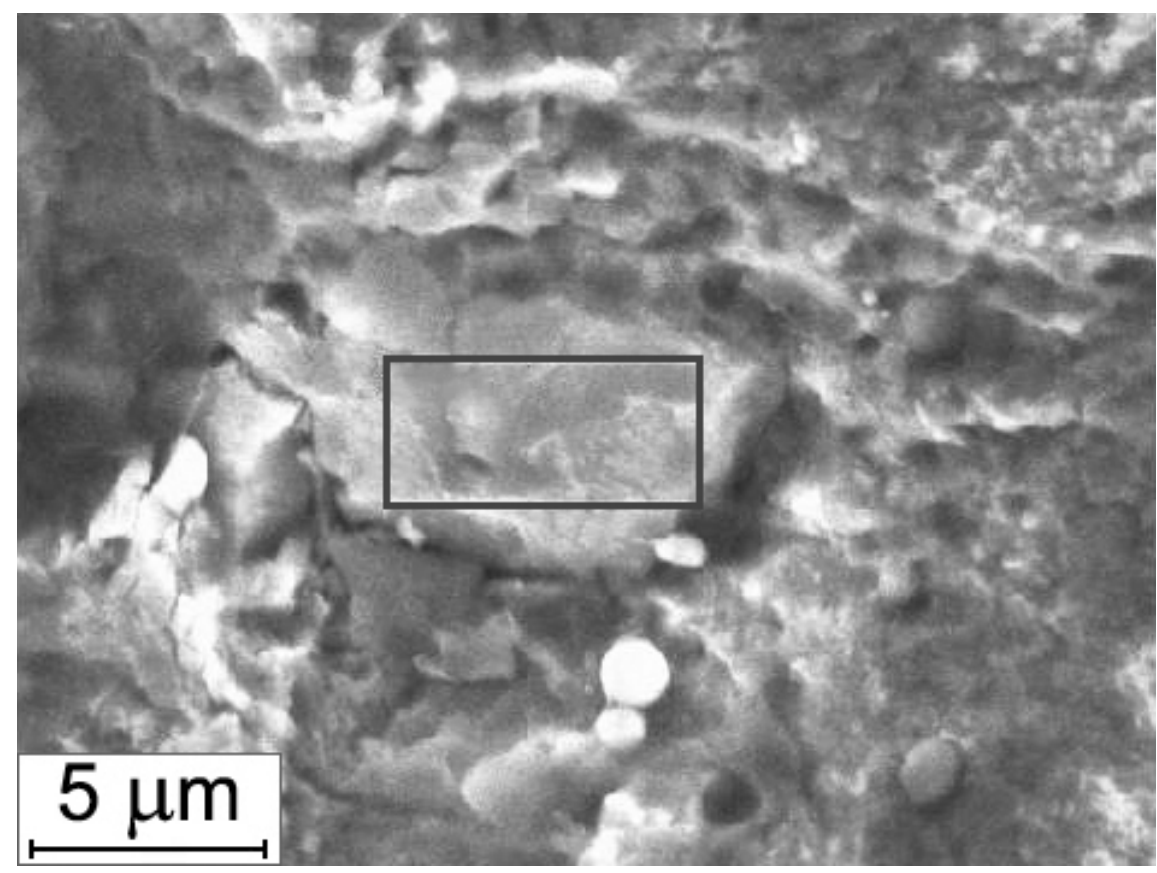

a)

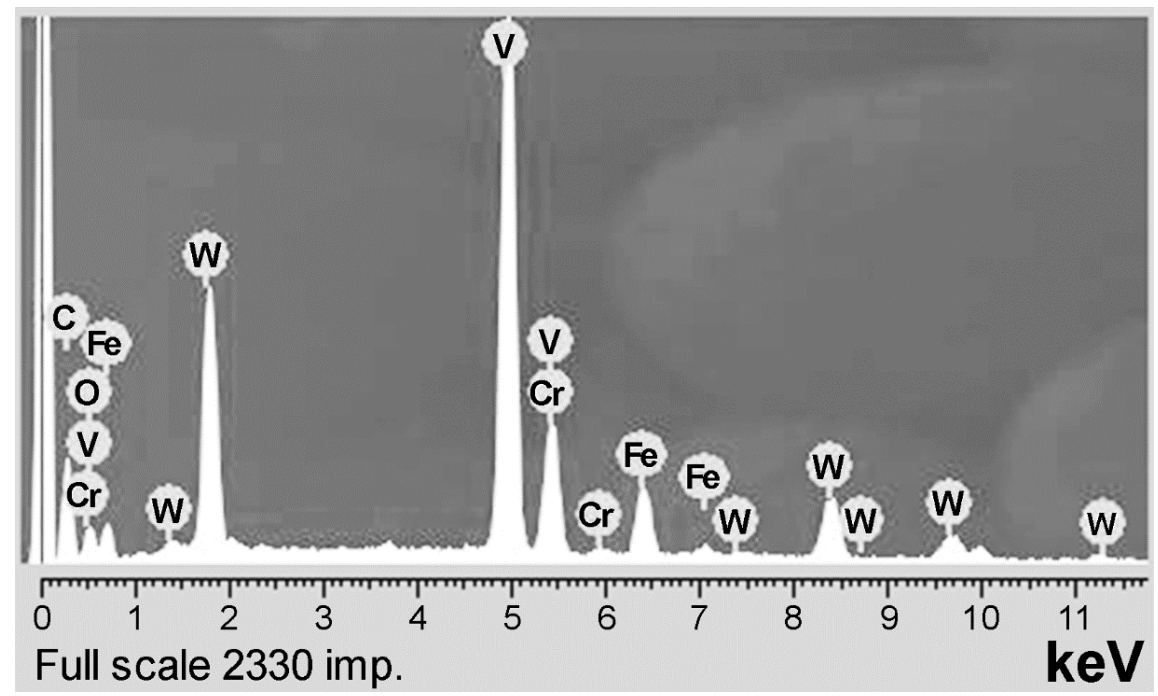

b)

Fig. 5. 


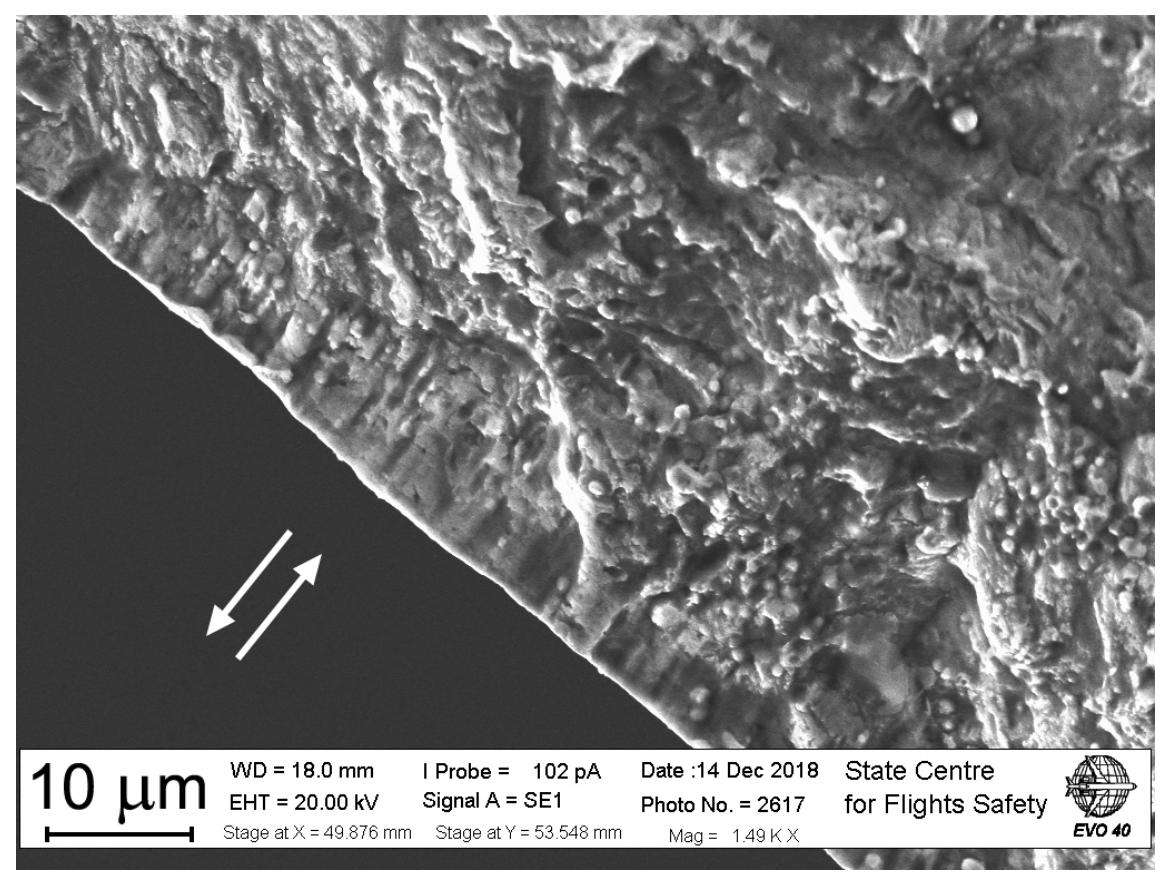

a)

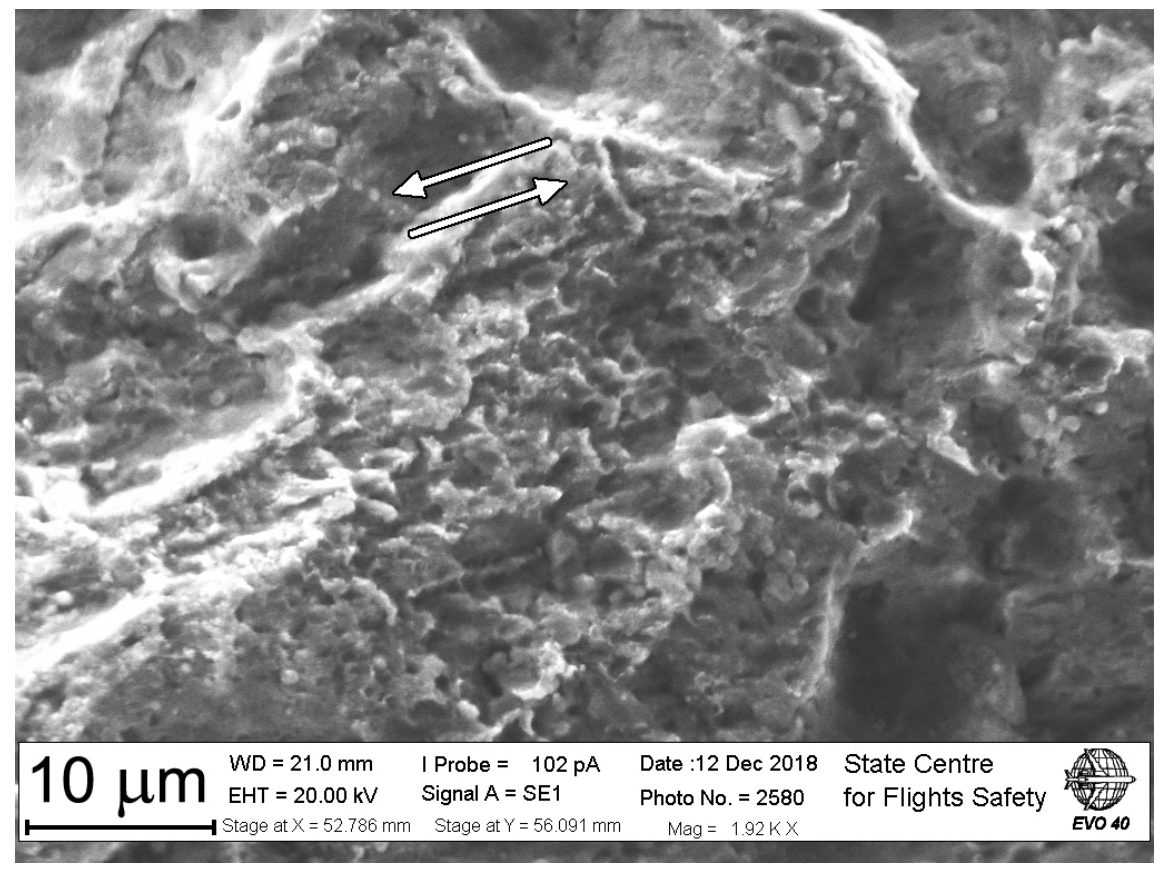

b)

Fig. 6 . 


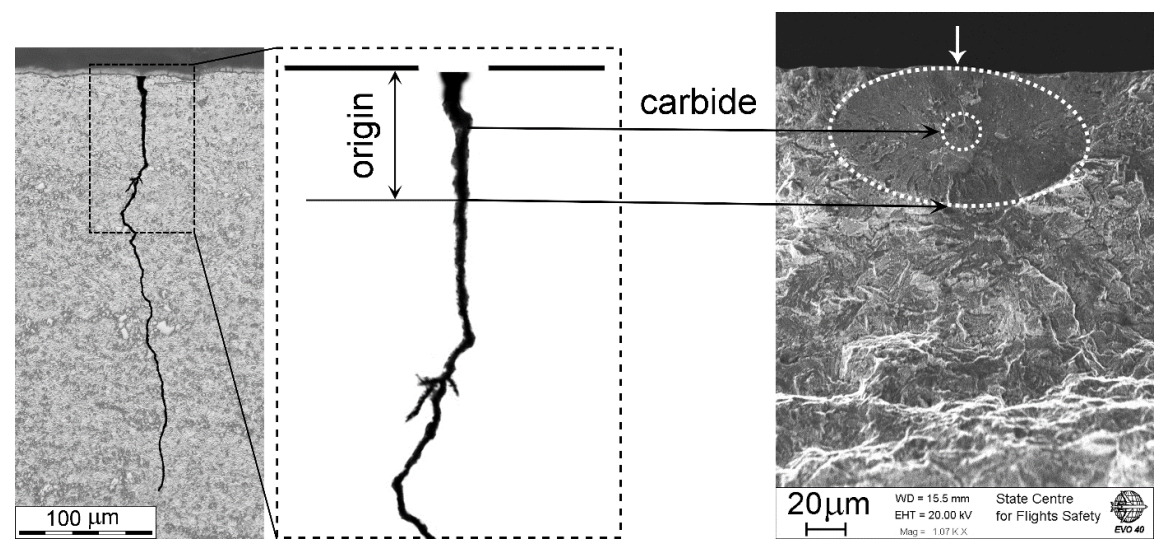

Fig. 7.

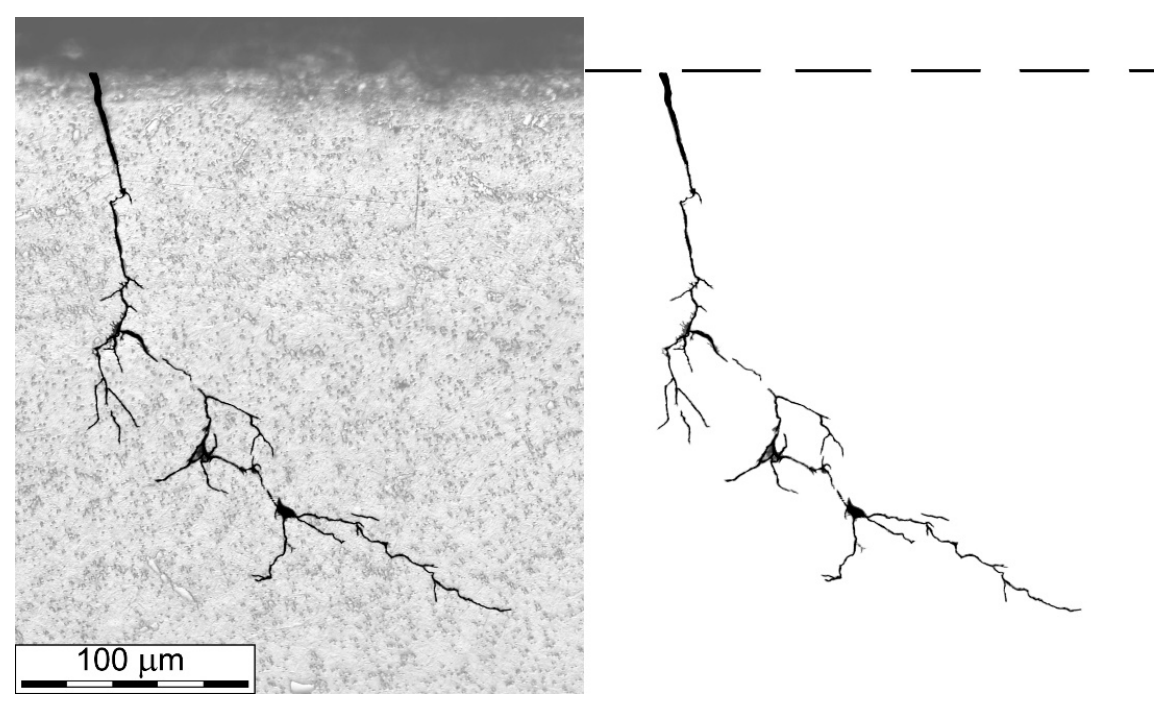

a)

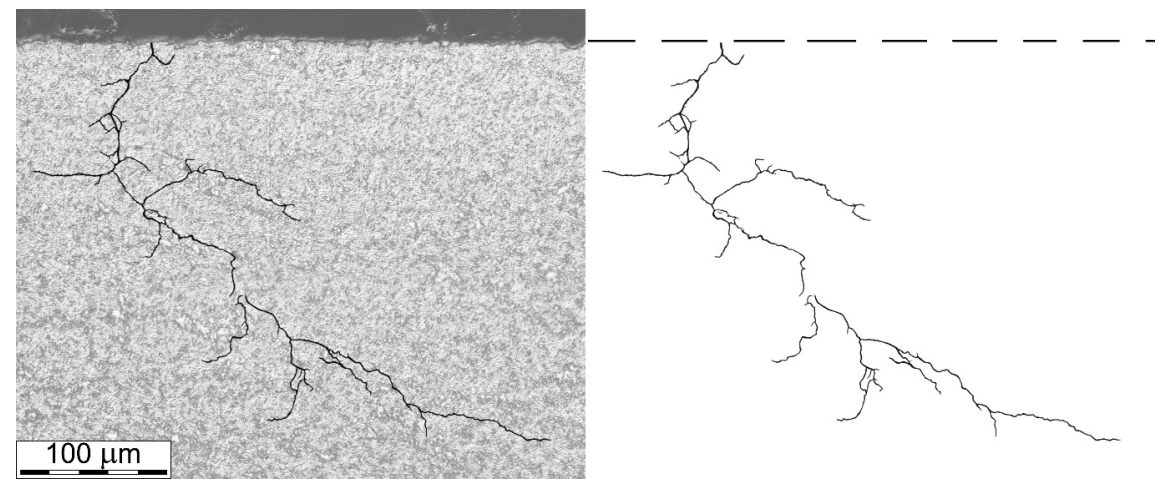

b)

Fig. 8 . 


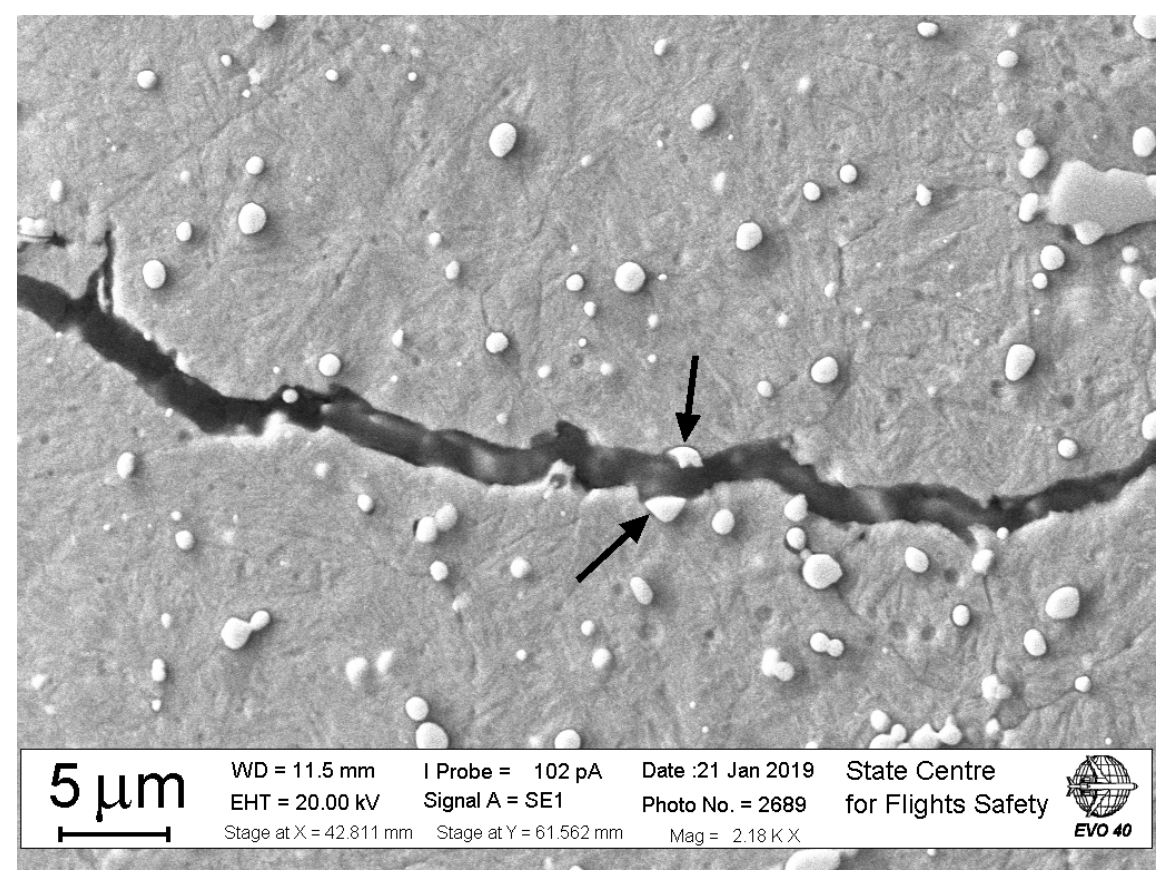

a)

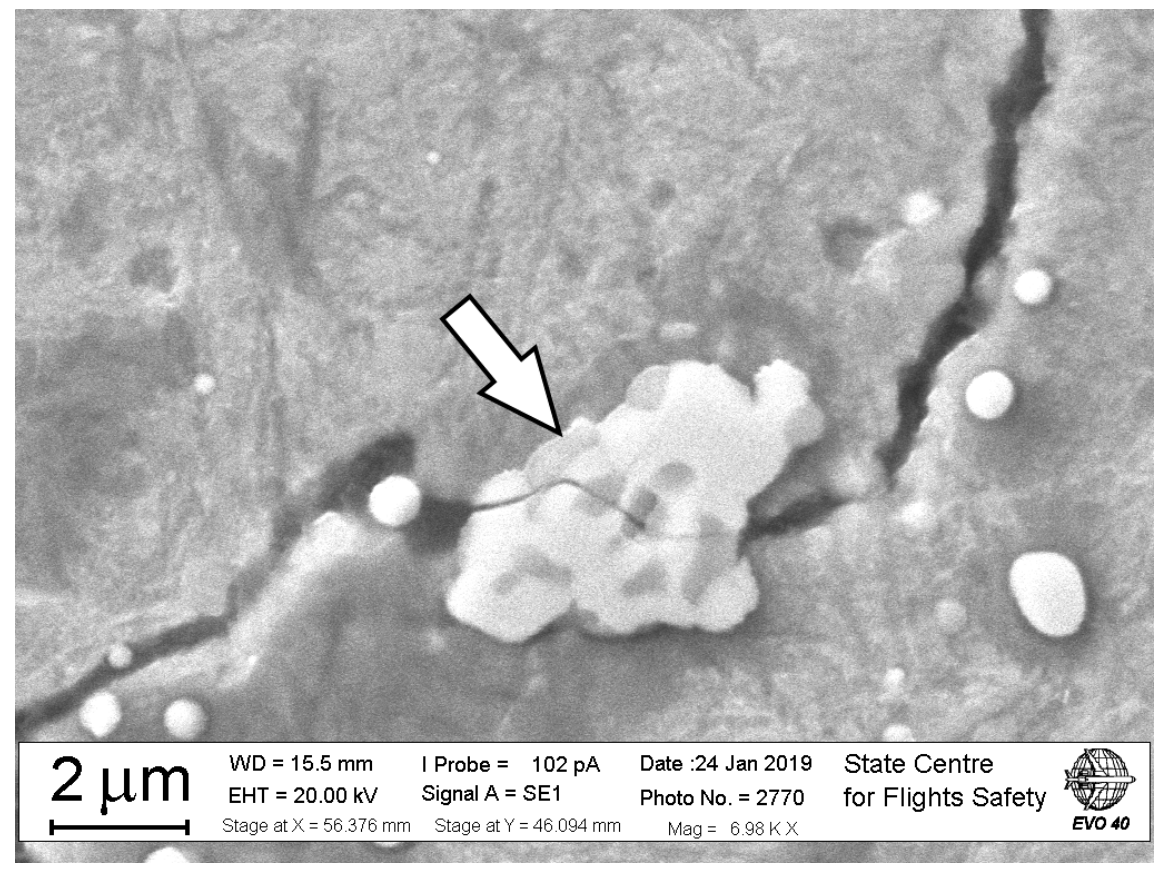

b)

Fig. 9. 


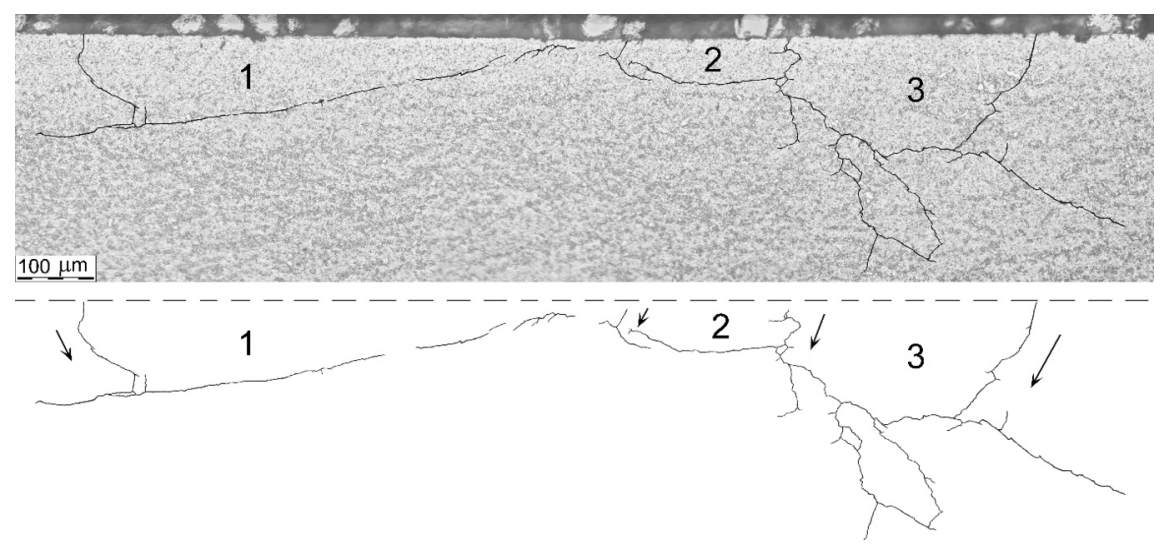

Fig. 10.

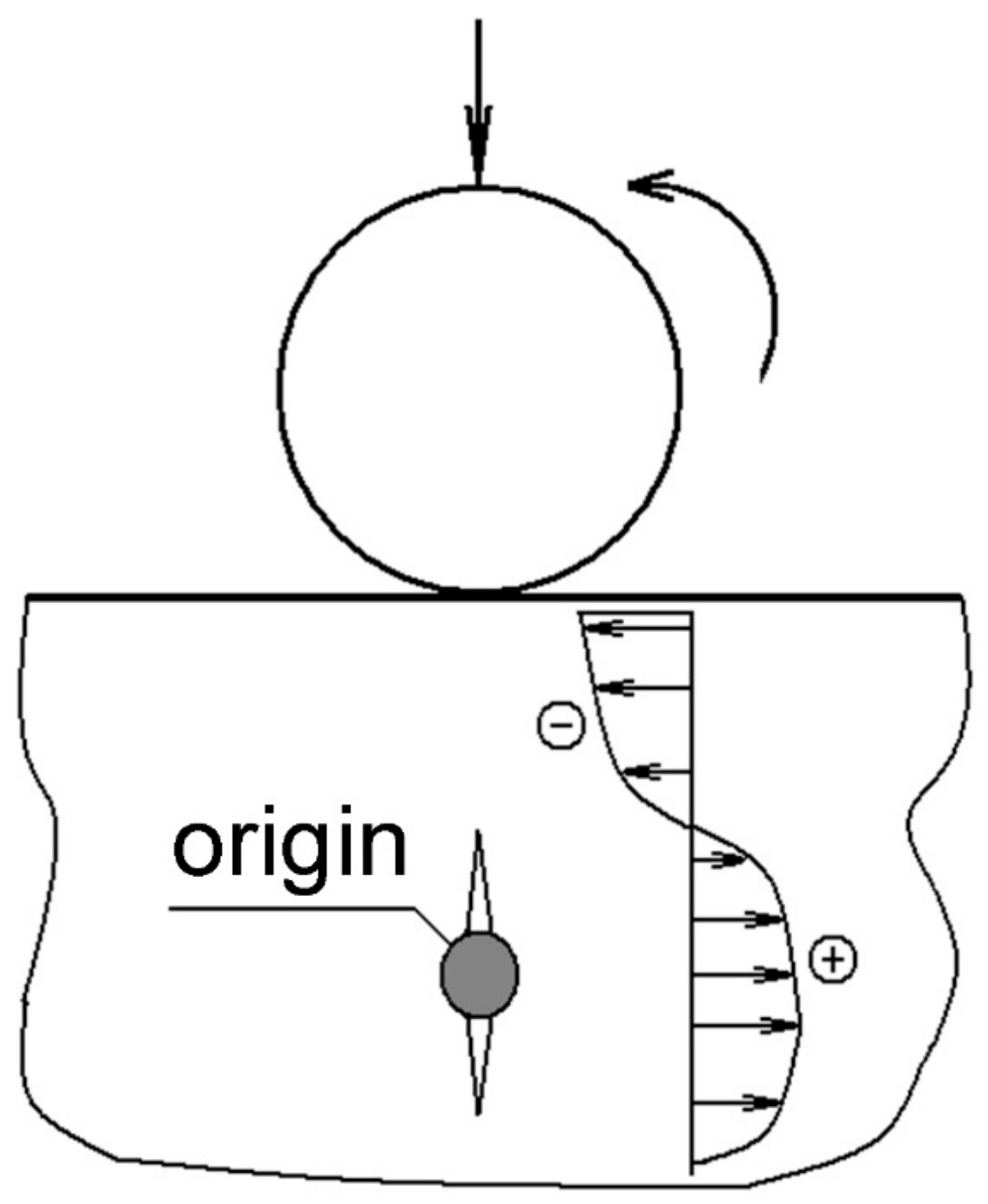




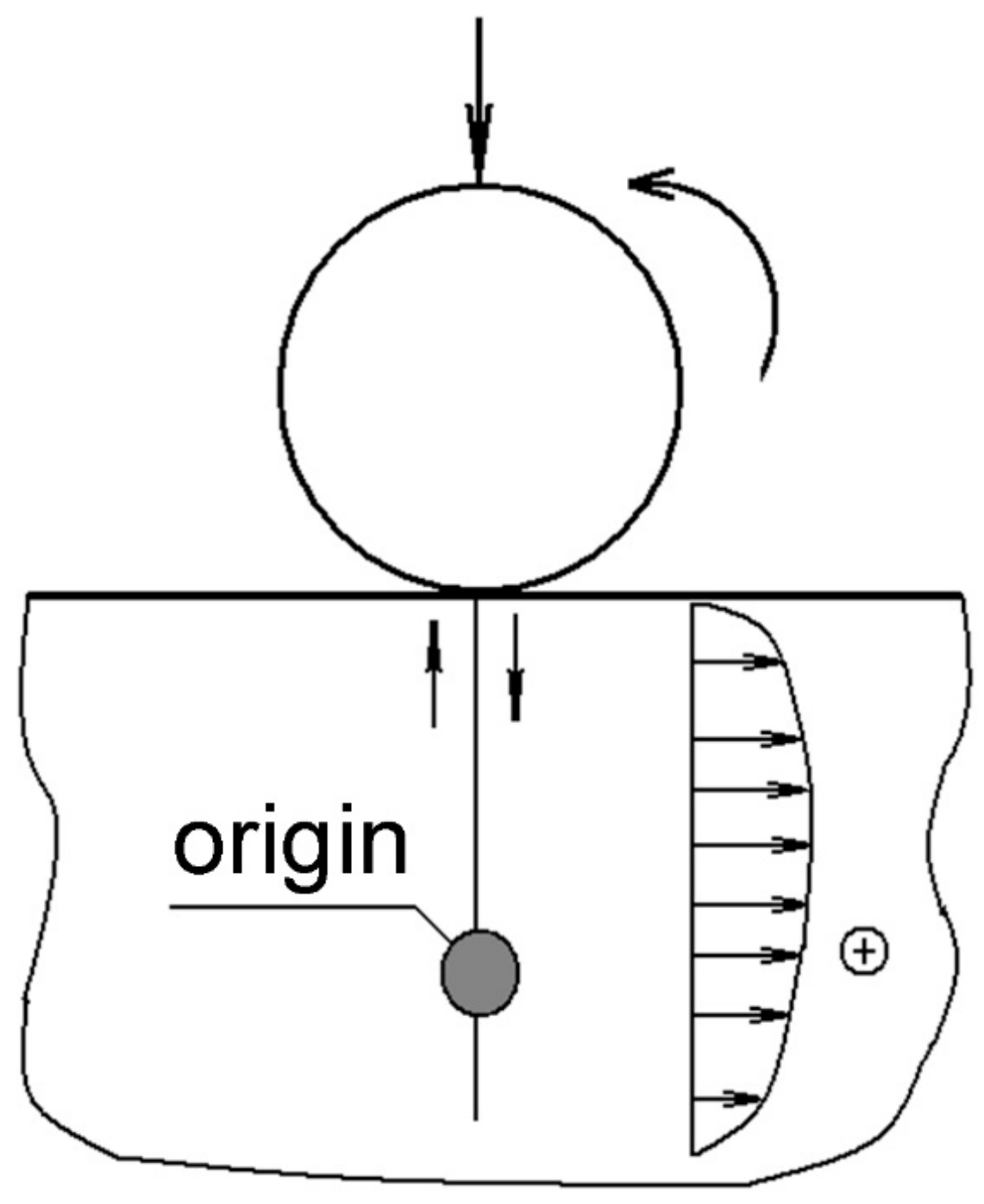

a) b)

Fig. 11.

Figure Captions

Fig. 1. Cracks of outer ring raceway in ball bearings (a) 76-211R and (b) 5-126215R, and (c, d) small fatigue spallings in the regions of crack coalescence at different magnifications.

Fig. 2. (a) Optical and (b, c) SEM images of bearing ring material structure at different magnification with spherical and angular carbides indicated by arrows in (c).

Fig. 3. Subsurface crack origins in outer rings for ball bearings (a, b) 76-211R and (c, d) 5-126215R.

Fig. 4. (a, b) Surface crack origins in outer rings of ball bearings.

Fig. 5. (a) Inclusion as angular carbide in the focus of subsurface crack origin in the outer ring of bearing 76-211R and (b) the corresponding spectrum of the chemical element distribution over the rectangular area indicated in (a). 
Fig. 6. The grooves from the spherical carbide displacements on the fracture surface (a) at the raceway surface and (b) in the depth of ring material under mixed-mode loading conditions due to the ball pressure. (The arrows indicate the direction of the crack face displacement.)

Fig. 7. The crack path at the initial stage of almost vertical crack growth observed in the radial section of the outer ring of the bearing along with the initial crack propagation zone on the fracture surface obtained from the crack previously studied on the slice. (The white arrow indicates the direction of the ball pressure.)

Fig. 8. Crack path with brunching $(\mathrm{a}, \mathrm{b})$ observed in radial sections located at different distances from the middle line of the outer ring raceway.

Fig. 9. The intersection of (a) spherical and (b) angular carbides during crack growth.

Fig. 10. Coalescence of adjacent branching cracks with the formation of material fragments (areas 1 to 3 ) for their subsequent separation at the initial stage of the fatigue spalling process. (The arrows indicate the growth direction for the initial propagation of cracks.)

Fig. 11. Scheme of (a) initial crack formation into a depth of material at inclusion and (b) subsequent propagation in a plane perpendicular to the raceway surface under dominant tensile loading conditions realized in subsurface due to ball pressure. 